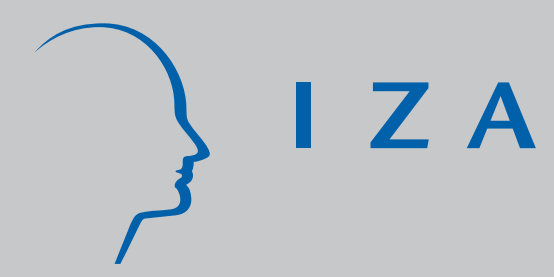

IZA DP No. 1756

Distribution of Natural Resources, Entrepreneurship, and Economic Development: Growth Dynamics with Two Elites

Josef Falkinger

Volker Grossmann

September 2005 


\title{
Distribution of Natural Resources, Entrepreneurship, and Economic Development: Growth Dynamics with Two Elites
}

\author{
Josef Falkinger \\ University of Zurich, \\ CESifo and IZA Bonn \\ Volker Grossmann \\ University of Zurich, \\ CESifo and IZA Bonn

\section{Discussion Paper No. 1756 \\ September 2005}

\author{
IZA \\ P.O. Box 7240 \\ 53072 Bonn \\ Germany \\ Phone: +49-228-3894-0 \\ Fax: +49-228-3894-180 \\ Email: iza@iza.org
}

\begin{abstract}
Any opinions expressed here are those of the author(s) and not those of the institute. Research disseminated by IZA may include views on policy, but the institute itself takes no institutional policy positions.

The Institute for the Study of Labor (IZA) in Bonn is a local and virtual international research center and a place of communication between science, politics and business. IZA is an independent nonprofit company supported by Deutsche Post World Net. The center is associated with the University of Bonn and offers a stimulating research environment through its research networks, research support, and visitors and doctoral programs. IZA engages in (i) original and internationally competitive research in all fields of labor economics, (ii) development of policy concepts, and (iii) dissemination of research results and concepts to the interested public.
\end{abstract}

IZA Discussion Papers often represent preliminary work and are circulated to encourage discussion. Citation of such a paper should account for its provisional character. A revised version may be available directly from the author. 


\section{ABSTRACT}

\section{Distribution of Natural Resources, Entrepreneurship, and Economic Development: Growth Dynamics with Two Elites*}

This paper develops a model in which the interaction of entrepreneurial investments and power of the owners of land or other natural resources determines structural change and economic development. A more equal distribution of natural resources promotes structural change and growth through two channels: First, by weakening oligopsony power of owners and thereby easing entrepreneurial investments for credit-constrained individuals whose investment possibilities depend on their income earned in the primary goods sector. Second, by shifting the distribution of political power from resource owners towards the entrepreneurial elite, resulting in economic policy and institutions which are more conducive to entrepreneurship and productivity progress. We argue that these hypotheses are consistent with a large body of historical evidence from the Americas and with evidence on transition economies.

JEL Classification: O10, H50

Keywords: credit constraints, distribution, economic development, entrepreneurship, institutions, oligopsony power, political elites

Corresponding author:

Volker Grossmann

Socioeconomic Institute

University of Zurich

Zürichbergstr. 14

$\mathrm{CH}-8032$ Zürich

Switzerland

Email: volker.grossmann@wwi.unizh.ch

\footnotetext{
* We are grateful to seminar participants at the workshop "Economic Growth and Institutions", University of Copenhagen, June 2005, and the University of Munich for valuable comments and suggestions.
} 


\section{Introduction}

Economic development is intimately related to structural change. The economic dimension of this change - the shift from agricultural or resource-intensive production to manufacturing and capital-intensive production - plays a central role in the growth literature. Another equally salient feature of historical development - the emergence of a bourgeois class as important economic and political force - has received less attention in the modern analysis of long-run growth dynamics. Our goal is to present an economic model which explains the interaction between growth, sectorial structural change and emergence of a second elite beside the traditional ruling class of natural resource owners. For this goal the following questions have to be answered: What is the economic role of the agents belonging to the new political force? Why are their political interests different from the interests of resource owners? Which factors determine size and political weight of the two elites? How can these factors explain the observed differences in the development paths of different economies?

The economic role for a new economic and political force comes from the fact that production and trade in the manufacturing sector requires agents who set up a business, the entrepreneurs. The relevant individual characteristic is whether or not an agent has the means to finance the cost of setting up a firm. Under credit constraints this depends on the agent's own income. The literature has identified important links between credit market imperfections and long-run growth patterns (Banerjee and Newman, 1993; Galor and Zeira, 1993; Bénabou, 1996; Aghion and Bolton, 1997; Piketty, 1997; Matsuyama, 2004; Aghion, Howitt and Mayer-Foulkes, 2005). The novel feature in our analysis is, because every economy in an early stage of development is dominated by primary goods production, the wage in the primary goods sector is a decisive financial determinant of the possibilities to start manufacturing activity. ${ }^{1}$ Hence, en-

\footnotetext{
${ }^{1}$ The entrepreneurial role leads to a new economic and political force - a second elite - only if this role is not adopted by the resource owners themselves. It is true that members of the traditional elite have more financial means to establish manufacturing firms than agents starting with saved wage income and credits. Nonetheless, as we will show later and consistent with our model, there is neither strong evidence that landowners have typically turned to entrepreneurship nor that they formed the political force promoting progress in favor of the manufacturing sector.
} 
trepreneurship, structural change and economic development critically depend on the oligopsony power in the labor market of the owners of land or other natural resources. This labor market power is determined by the ownership concentration of natural resources.

The political role of the entrepreneurs results from the fact that their interests regarding productivity progress and structural change don't coincide with the interests of the natural resource owners. The possibilities of resource owners to extract rents from their property depend on the volume of labor supplied to the primary sector. Political or institutional changes like public education, entry liberalization or financial development, which favor entrepreneurial investments and employment in the manufacturing sector, are therefore not in their interest. In contrast, entrepreneurs profit from policies which raise manufacturing productivity, for instance a literate labor force. Ceteris paribus, the larger the entrepreneurial elite, the larger is their political weight and the more favorable implemented policies are for development.

Combining the economic role of entrepreneurship, the different political interests of entrepreneurs and resource owners, and the factors determining the political weight of the two elites, we can identify the main causes responsible for different development paths and institutions. High oligopsony power in the primary goods sector - resulting from strong concentration of resource ownership - is a hurdle to entrepreneurial investments in manufacturing. This directly impedes structural change and productivity growth. Moreover, it hinders the emergence of a bourgeois class so that resource owners remain the dominant political force. They have no interest in promoting structural change and manufacturing productivity, for instance, by supporting public education, entry liberalization or financial development. In contrast, under a more egalitarian distribution of resources, starting a business in the manufacturing sector is easier, which triggers a virtuous circle of economic and political change.

Our theory contributes to the important debate on differential development paths across countries by linking structural change, economic policy, the institutional environment, and growth to a variable which can be viewed as truly exogenous in many 
development contexts: the initial distribution of natural resources. One prime example of a quasi-natural experiment in which colonial heritage determined the initial resource distribution is the case of the Americas. Consistent with our theory, there have not only been substantial differences in development patterns across the Americas, ${ }^{2}$ but also dramatic differences in the inequality of land distribution. For instance, according to Engerman and Sokoloff (2005, Tab. 4), in the very beginning of the twentieth century the proportion of household heads who owned land was 74.5 percent in the United States and 87.1 percent in Canada but only 2.4 percent in rural Mexico. ${ }^{3}$ In Argentina, land inequality was less dramatic than in Mexico, with regional differences in the proportion of landowners, ranging from 6.6 percent to 35.2 percent. $^{4}$

In line with our theory, Fig. 1 suggests that these patterns of land inequality across North and South America, and divergence in per capita income, are associated with dramatic differences in the evolution of the agricultural share and primary school enrollment. Panel (a) shows the evolution of the share of employment in the agricultural sector from 1880-1930, which was basically stable in Mexico and Brazil at circa 2/3, slowly going down in Argentina from 42 to 36 percent, and sharply declining in the United States and Canada from about 50 percent to 22 and 31 percent, respectively. ${ }^{5}$ Also differences in primary school enrollments were dramatic. In 1880, primary school enrollment was already 80 percent in the U.S. and Canada but below 20 percent in the three Latin American countries. Over time, however, and consistent with our hypothesis that an emerging entrepreneurial class has eventually gained political weight vis-à-vis resource owners and affected economic policy in a way which is favorable to industrial development, primary school enrollments roughly doubled until 1930 in Mexico and Brazil towards 37 and 22 percent, respectively, and increased from 14 to

\footnotetext{
${ }^{2}$ Although Latin America as a whole had similar per capita income in the 18th century as North America, nowadays, per capita GDP of North America exceeds that of Latin America by a factor of almost five (Maddison, 2003, Tab. 4-1).

${ }^{3}$ For Chile, McBride (1936) reports that 89 percent of rural land were divided by only 5396 estates in 1925.

${ }^{4}$ Also, Argentina was the most developed Latin American country in the first half of the twentieth century, but nevertheless their development indicators lacked far behind those of North America.

${ }^{5}$ These figures are mimicked by data on industrial output provided by Bairoch (1982), which shows very slow increases in Mexico and Brazil and sharp increases in the U.S. and Canada.
} 


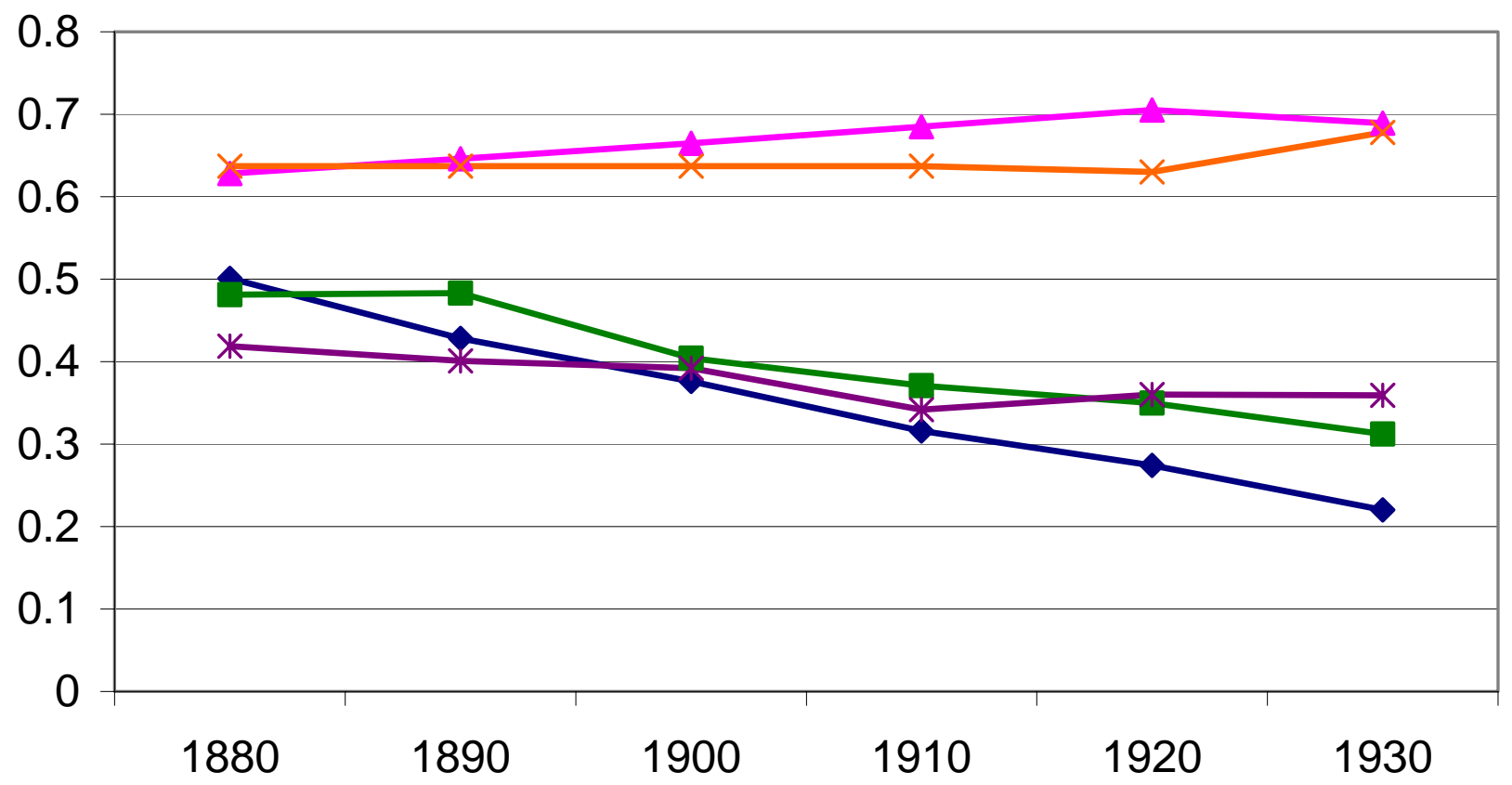

(a) Agricultural share of labor force

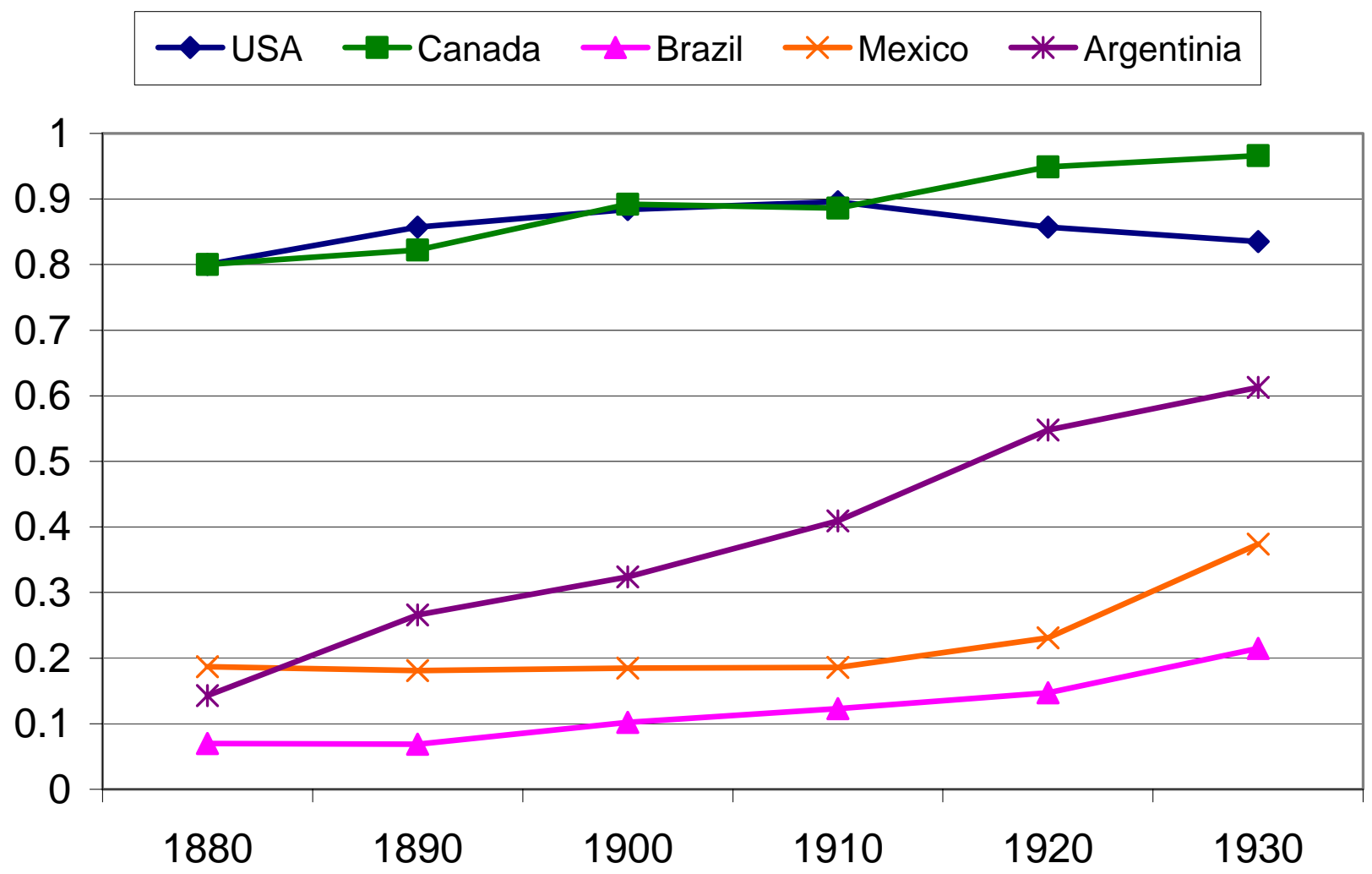

(b) Primary school enrolment

Figure 1: Development indicators for the Americas, 1880-1930.

Data Source: Lindert, Peter. http://www.econ.ucdavis.edu/faculty/fzlinder/ 
61 percent in Argentina. (We will provide more detailed evidence which supports the specific mechanisms suggested by our analysis in section 7.)

The plan of the paper is as follows: Section 2 briefly discusses related literature. Section 3 presents the economic model. The economic equilibrium is characterized in section 4 . In section 5 the political equilibrium is analyzed, in particular the level of public education resulting in equilibrium as well as institutional regulations affecting entry costs and financial constraints. Section 6 highlights the interaction between the distribution of natural resources and economic development. Section 7 shows that our results are well supported by ample historical evidence from the Americas and also sheds light on development patterns in transition economies. Section 8 provides concluding remarks. All proofs are relegated to an appendix.

\section{Related Literature}

Although links between land inequality and economic development have long been discussed by economic historians, there are only a few attempts to develop formal models on the interrelation of these variables. Galor, Moav and Vollrath (2005) show that land inequality is negatively related to the point of time in which landowners support public education conducive to growth. There are important differences to our model. First, in their model landowners will eventually be in favor of mass education (because they own the bulk of the capital stock and there is capital-skill complementarity), whereas our model predicts a continued political struggle between the initially ruling class of resource owners and the emerging entrepreneurial class, with a gradual shift of political power towards the entrepreneurial elite. Second, apart from political forces, our theory proposes a novel economic channel - based on oligopsony power of resource owners and credit constraints of potential entrepreneurs - how the distribution of natural resources affects development. In Falkinger and Grossmann (2005) we propose a theory in which the opposition of the landed elite to mass education is related to openness to trade, where an open trade regime is politically supported by the landed elite under a 
comparative advantage for primary goods production. ${ }^{6}$ However, also this model does not explain the emergence of an entrepreneurial class with different interests than the traditional elite.

Another strand of literature deals with the interaction between inequality, rule of law and democratication. Gradstein (2004) shows how initial inequality negatively affects economic development by lowering the quality of institutions (democracy and property rights protection) in political equilibrium (see also Chong and Gradstein, 2005). ${ }^{7}$ Gradstein and Justman (1999) argue that democratization in 19th-century Great Britain has led to significant reductions in the inequality of income, to adoption of free public education, and to further extensions of the franchise. In contrast to this literature, we are interested in the economic and political forces that lead to sectorial structural change (analyzing a two-sector model). Our goal is to understand the role of the resource distribution for the economic and political equilibrium in economies characterized by the rule of elites (with possibly different interests) rather than the transition to democratization. ${ }^{8}$

Finally, our analysis is related to the debate on the resource curse. There is indeed plenty of evidence from the last decades that resource-abundance has been an obstacle to development (Gylfason, 2001; Sachs and Warner, 2001). Theoretical explanations point to a crowding-out of sectors which exhibit static or dynamic increasing returns to scale (Matsuyama, 1992; Gylfason, Herbertson and Zoega, 1999), to rent-seeking (Lane and Tornell, 1996; Torvik, 2002; Hehlum, Moene and Torvik, 2005) and low quality of institutions (Easterly and Levine, 2003) in economies with natural resources. In

\footnotetext{
${ }^{6}$ Galor and Mountford (2003) propose a purely economic mechanism (unrelated to political power) how trade may have contributed to diverging development patterns. They argue that specialization of unskilled labor-abundant countries in primary goods production has led to a substantial delay in demographic transition to lower birth rates, whereas industrial nations specialized in skill-intensive goods and thus invested in education.

${ }^{7}$ Acemoglu, Johnson and Robinson (2005) provide an excellent survey on the literature on democratization and property rights protection.

${ }^{8}$ In fact, many economies with high concentration of resource ownership like Latin America until fairly recently or today's transition economies are typically governed by elites - be it through direct political representation, corruption or lobbying. Glaeser et al. (2004) provide evidence that human capital accumulation is a better predictor of economic growth than institutions. It may be encouraged also by non-democratic governments.
} 
contrast, our analysis suggests that not the abundance of natural resources per se but the fact that natural resources are typically in the hands of a small oligarchy in resource-abundant economies is the main obstacle to development.

\section{The Model}

We consider an overlapping generations economy with two-period lives.

\subsection{Endowments}

Individuals differ in factor endowments. There is a "traditional elite", represented by discrete number of $N^{R}>1$ households, who own some natural resource (e.g. land, minerals or oil). ${ }^{9}$ In each period, a household consists of parent and child, where the child becomes parent in the second period of life and inherits the owned resource. The total amount of resources is time-invariant and denoted by $R$. This fixed factor is equally distributed among resource owners, each owning $\rho=R / N^{R}$. The rents from the fixed factor are shared within a household of the traditional elite between parent and child.

Moreover, in each period a large number $N^{L}$ of individuals, called "laborers", is born. They are identically endowed with raw labor in the first period of life but don’t own resources. Besides raw labor, laborers are also endowed with an ability $1-\xi$ to become entrepreneur, as specified in more detail in the next subsection. The distribution of $\xi$ among the $N^{L}$ individuals is time-invariant and uniform on the unit interval. When not becoming entrepreneur, laborers retire in the second period of life.

Throughout, we measure the equality of the resource distribution by the ratio $n^{R}=$ $N^{R} / N^{L}$, which is one-to-one related to the share of resource owners in total population. To focus on the role of the resource distribution, we normalize $R=N^{L}$, so that $\rho$ (resource ownership per elite member) is inversely related to $n^{R}$.

\footnotetext{
${ }^{9}$ For instance, the traditional oligarchy in 19th century South America mainly consisted of big landowners. Some of them made their fortune from mining.
} 


\subsection{Technology}

There are two sectors, a primary goods $(X-)$ sector, like agriculture or mining, which is resource-intensive, and a manufacturing $(Y-)$ sector. Goods markets are perfectly competitive.

Resource owners produce the $X$-good. Output $x_{t}$ of each resource owner in period $t$ is given by a linearly homogenous production function $F$ :

$$
x_{t}=F\left(l_{t}^{x}, \rho\right) \equiv \rho f\left(l_{t}^{x} / \rho\right),
$$

where $l_{t}^{x}$ is the amount of labor a single resource owner employs in period $t . f(\cdot)$ is an increasing and strictly concave function which fulfills the standard boundary conditions. Production of the primary good also requires supervision of resource owners, which does not allow them to manage a manufacturing firm at the same time. We will show that the profit earned by resource owners increases with their endowment $\rho$ of the fixed factor. Therefore, if $\rho$ is sufficiently high, a resource owner will not find it attractive to become entrepreneur. We assume throughout that their endowment $\rho$ is high enough to satisfy this incentive condition.

The manufacturing good is produced according to a simple constant returns to scale technology with labor as only input. However, starting a business in which $l_{t}^{y}$ units of labor can be employed in $t$ involves set up costs. An individual with ability $1-\xi$ has to invest

$$
k\left(\xi, l_{t}^{y}\right)=\bar{k}+\xi+0.5\left(l_{t}^{y}\right)^{2}
$$

units of capital in $t-1,{ }^{10}$ which allows to produce output

$$
y_{t}=A_{t} l_{t}^{y}
$$

in the second period of life. $A_{t}$ is manufacturing productivity in $t$. Parameter $\bar{k} \geq 0$

\footnotetext{
${ }^{10}$ Thus, higher ability of an individual to become entrepreneur reduces the part of the set up costs which is unrelated to employment capacity $l_{t}^{y}$. This assumption simplifies the analysis of the case where credit constraints are non-binding. It is not crucial for any of our main results.
} 
captures both technological set up requirements and entry costs associated with the institutional environment of the economy. For instance, barriers to entry are related to the level of corruption, property rights protection and rule of law (Djankov et al., 2002), which are standard indicators in the literature on institutions and development. ( $\bar{k}$ is politically determined in section 5 .)

Let $N_{t}^{E}$ be the (endogenously determined) number of entrepreneurs in $t$, where the number of entrepreneurs among the initially old, $N_{0}^{E}>0$, is given. Also the initial number of (young) laborers employed by the $N_{0}^{E}$ entrepreneurs, $L_{0}^{Y}>0$, is given.

\subsection{Credit Market}

We follow Aghion, Howitt and Mayer-Foulkes (2005) in assuming that the credit market is imperfect in the following sense. An entrepreneur, who is a dependent worker in the first period of life, cannot borrow more than a finite multiple of first period (wage) income, $I$. More formally, (s)he cannot invest more than $\eta I, 1 \leq \eta<\infty$. $^{11}$ Together with set up costs in (2), this restricts the possibilities for laborers to become entrepreneur. Parameter $\eta$ captures the financial development of the economy, where $\eta=1$ means that no credit market exists. If $\eta$ is sufficiently large the credit constraint is not binding.

\subsection{Preferences and Individual Labor Supply}

For simplicity, suppose the $X-$ and $Y-$ good are perfect substitutes, where both prices are equal to unity. Instantaneous utility of individuals from consumption in the first and second period of life is identical and linear in consumption. To save notation, suppose the discount rate is zero, and equal to the interest rate. ${ }^{12}$ Thus, individuals are indifferent between present and future consumption.

\footnotetext{
${ }^{11}$ See also Bernake and Gertler (1989). Aghion, Howitt and Mayer-Foulkes (2005) provide a simple microfoundation. Let $r$ denote the interest rate and suppose an entrepreneur who invests $k$ can defraud the creditors by paying a cost $\mu k, 0 \leq \mu<1+r$. To do this is not worthwhile if $\mu k \geq(1+r)(k-I)$, which is equivalent to $k \leq \eta I, \eta \equiv(1+r) /(1+r-\mu)$. Thus, the maximum amount of investment is $\eta I$, where $\eta \geq 1$.

${ }^{12}$ Allowing for a positive interest (and discount) rate would not affect the predictions of our model.
} 
Let $w$ denote the wage rate. Individual labor supply $s$ is positively sloped and takes the simple isoelastic form: $s(w)=\bar{s} w^{1 / \vartheta}, \bar{s}>0$, where the elasticity of labor supply, $1 / \vartheta$, is constant. Each worker can supply labor to only one sector at once.

\subsection{Labor Market}

The labor market in the $X$-sector is oligopsonistic. Resource owners hire workers to maximize profits by taking the hiring of other resource owners as given. Note that capacity investment decisions by entrepreneurs in $t$ are already made in the previous period. Resource owners rationally anticipate that total employment capacity installed in $t-1$ will equal actual employment (of young laborers) in the manufacturing sector in $t, L_{t}^{Y}$. The implied number of individuals who supply labor to the $X$-sector in $t$ is

$$
N_{t}^{X}=N^{L}-L_{t}^{Y}
$$

Resource owners therefore face a labor supply schedule $L_{t}^{X}=N_{t}^{X} s(w)$. Observing this schedule, they simultaneously choose labor demand $\left(l^{x}\right)$ to maximize profits $\pi^{x}=$ $\rho f\left(l^{x} / \rho\right)-w l^{x}$ in a non-cooperative way. Noting that $\vartheta$ is the elasticity of inverse labor supply (reflecting oligopsony power of resource owners), the wage rate in the $X$-sector follows the standard oligopsony formula: ${ }^{13}$

$$
w_{t}^{X}=\frac{f^{\prime}\left(l_{t}^{x} / \rho\right)}{1+\vartheta / N^{R}}
$$

Thus, except in the limit case in which labor supply is fully elastic $(\vartheta=0)$, wages in the $X$-sector are below their marginal product. Equ. (5) also implies that, when $\vartheta>0$, resource owners will be better able to exploit their market power the lower their number $N^{R}$, all other things equal.

The wage rate in the manufacturing sector, $w^{Y}$, is proportional to total factor

\footnotetext{
${ }^{13}$ To see this, use $L^{X}=N^{X} s(w)$ and $s(w)=\bar{s} w^{1 / \vartheta}$ to find $w=\left(L^{X} / \bar{s} N^{X}\right)^{\vartheta}$ for inverse labor supply. Simultaneous profit maximization of resource owners (where each owner takes the hiring of others as given) then yields (5) in symmetric Nash equilibrium, in which $l^{X}=L^{X} / N^{R}$.
} 
productivity:

$$
w_{t}^{Y}=\alpha A_{t}
$$

As shown in Appendix A, this can be rationalized either by Nash bargaining between single workers and entrepreneurs or by efficiency wage considerations of entrepreneurs. Both possibilities are plausible. Nash bargaining reflects the idea that a specific workerfirm relationship is important in manufacturing (in contrast to the $X$-sector). Similarly, efficiency wage setting in the $Y$-sector captures the notion that effort in the manufacturing sector is more difficult to monitor than in the primary goods sector. We assume throughout that the manufacturing sector is not less attractive for laborers than the primary goods sector, such that entrepreneurs are always able to utilize all capacity they want to install at this wage. ${ }^{14}$ For simplicity, we also assume that entrepreneurs offer (e.g., for organizational reasons) only full-time positions with individual working time normalized to unity. That is, $w^{Y}$ equals earnings of a laborer who is employed in the manufacturing sector, whereas individual wage income in the $X$-sector, $I^{X}$, is given by $I^{X}=w^{X} s\left(w^{X}\right)$.

\subsection{Productivity Growth}

Labor productivity in the manufacturing sector changes over time due to spillovers and learning-by-doing effects across entrepreneurs. This is captured by assuming that $A_{t+1}$ is an increasing function of the share of entrepreneurs among laborers in the previous period, $n_{t}^{E}=N_{t}^{E} / N^{L} \cdot{ }^{15}$ Moreover, productivity $A_{t+1}$ is positively related to the level of public input per laborer, denoted by $G_{t+1}$, which may be interpreted as public education expenditure or the provision of infrastructure. (The stream of public investment levels, $G_{t}, t \geq 1$, is determined in the political analysis of section 5 .) Finally, as technical progress builds on the existing stock of knowledge, $A_{t+1}$ depends positively on current productivity $A_{t}$, where $A_{0}>0$ is given. More formally, $A$ evolves

\footnotetext{
${ }^{14}$ Positive wage income differentials between manufacturing and agriculture is consistent with overwhelming evidence on a positive (real) urban-rural wage gap. For instance, Hatton and Williamson (1992) provide historical data on the U.S. for the period 1890-1941, and discuss related evidence.

${ }^{15}$ Recall that $N^{L}$ is the pool of potential entrepreneurs.
} 
over time according to

$$
A_{t+1}=a\left(n_{t}^{E}, G_{t+1}, A_{t}\right)
$$

where function $a$ is increasing in its arguments. For a given $G_{1}, A_{1}=a\left(n_{0}^{E}, G_{1}, A_{0}\right)$ is determined by initial conditions. Whereas the stock of knowledge and public infrastructure or education are standard factors in the literature on endogenous productivity growth, a key feature of our model is that economic development is driven by entrepreneurship, which will itself depend on both economic and political factors.

\section{Economic Equilibrium}

In this section we solve the model for a given stream of public investment levels $\left(G_{t}\right.$, $t \geq 1$ ) and given institutional parameters $\bar{k}$ and $\eta$.

We start with a characterization of the oligopsony equilibrium in the $X$-sector. Let $n_{t}^{X}=N_{t}^{X} / N^{L}$ be the share of workers who supply labor in the $X$-sector at date $t$. According to (4), from the perspective of the resource owners this share is given. The following intuitive result holds. (All proofs can be found in the appendix.)

Lemma 1. An increase in $n_{t}^{X}$ reduces equilibrium wage income in the primary goods sector in period $t, I_{t}^{X}$, and, if $\vartheta>0$, raises profits, $\pi_{t}^{x}$, earned by a resource owner in $t$. Moreover, for a given $n_{t}^{X}$, an increase in $n^{R}$ (equality of the resourcedistribution) reduces profits, $\pi_{t}^{x}$, and, if $\vartheta>0$, raises $I_{t}^{X}$.

First, for any $\vartheta \geq 0$, the larger the share of laborers, $n^{X}$, who seek employment in the resource-intensive sector, the lower is the marginal return to labor and thus, the labor input per worker in the $X$-sector. This depresses wage income $I^{X}=w^{X} s\left(w^{X}\right)$. Second, a larger labor force in the $X$-sector allows resource owners to better exploit their oligopsony power (if they have any, i.e., if $\vartheta>0$ ); hence, an increase in $n^{X}$ has a positive impact on their profits. Finally, resource owners can exert less oligopsony power when the ratio of resource owners to laborers, $n^{R}$, is higher, i.e., the more equally resource endowments are distributed. Thus, workers' earnings in the primary goods 
sector, $I^{X}$, increase with $n^{R}$.

In the remainder of this section, we will analyze the decision of laborers whether or not to become entrepreneur and the implications for economic development. We will compare two regimes: first, when credit constraints for financing entrepreneurial investments are non-binding ( $\eta$ is sufficiently large) and second, when binding for at least some laborers.

\subsection{Unconstrained Regime}

When credit constraints are non-binding or absent ("unconstrained regime"), optimal employment capacity in $t$ of an entrepreneur with ability $1-\xi$ maximizes net profits $^{16}$

$$
\pi_{t}^{y}(\xi)=\left(A_{t}-w_{t}^{Y}\right) l_{t}^{y}-k\left(\xi, l_{t}^{y}\right)
$$

Using $w_{t}^{Y}=\alpha A_{t}$ and $k\left(\xi, l^{y}\right)=\bar{k}+\xi+0.5\left(l_{t}^{y}\right)^{2}$, we obtain for optimal capacity (i.e., firm size)

$$
l_{t}^{y *}=(1-\alpha) A_{t}
$$

which is independent of both $\xi$ and $\bar{k}$. Higher manufacturing productivity, $A$, raises the marginal profit from investments and therefore raises optimal capacity. Optimal entrepreneurial capacity choice implies profits

$$
\pi_{t}^{y *}(\xi)=0.5(1-\alpha)^{2} A_{t}^{2}-\xi-\bar{k}
$$

Whenever $\pi_{t}^{y *}(\xi) \geq 0$, a laborer born in $t-1$ becomes entrepreneur in $t \geq 1$. This is equivalent to

$$
\xi \leq 0.5(1-\alpha)^{2} A_{t}^{2}-\bar{k} \equiv \xi_{t}^{*}
$$

i.e., a laborer becomes entrepreneur if $\xi$ is below some threshold level, $\xi_{t}^{*},{ }^{17}$ which positively depends on manufacturing productivity $A_{t}$ and negatively on fixed costs $\bar{k}$. Recall that $\xi$ is uniformly distributed on the unit interval. Thus, if no laborer is

\footnotetext{
${ }^{16}$ Since the interest rate is assumed to be zero, future profits $\left(A_{t}-w_{t}^{Y}\right) l_{t}^{y}$ are not discounted.

${ }^{17}$ We focus on parameter configurations such that $\xi_{t}^{*} \in(0,1)$ for all $t \geq 1$.
} 
credit-constrained, then the equilibrium share of entrepreneurs is given by $n_{t}^{E *}=\xi_{t}^{*}$. Consequently, the evolution of manufacturing productivity is characterized by $A_{t+1}=$ $a\left(\xi_{t}^{*}, G_{t+1}, A_{t}\right)$, according to $(7)$.

Fig. 2 illustrates the convergence pattern of manufacturing productivity for a constant level of public investments $G_{t}=G$, when there exists a unique and stable steady state productivity level $A(G)$. If $G$ is increased the curve in Fig. 2 moves upwards and the steady state productivity level rises. As an example, take

$$
a\left(n^{E}, G, A\right)=\left(n^{E}\right)^{\gamma} h(G) A^{\varepsilon}+(1-\delta) A,
$$

where $\gamma, \delta, \varepsilon>0$ and $h$ is an increasing function with $h(0)>0 .{ }^{18} \bar{k}=0$ and $2 \gamma+\varepsilon<1$ are sufficient to guarantee a unique and stable steady state. ${ }^{19}$

Since all entrepreneurs $\left(N^{E}=n^{E} N^{L}\right)$ choose the same capacity, irrespective of their ability, total employment in the $Y$-sector is $L^{Y}=N^{E} l^{y}$. Thus, manufacturing output per laborer, $Y_{t}=A_{t} L_{t}^{Y} / N^{L}$, is given by

$$
Y_{t}^{*}=A_{t} \xi_{t}^{*} l_{t}^{y *}=(1-\alpha) A_{t}^{2}\left[0.5(1-\alpha)^{2} A_{t}^{2}-\bar{k}\right]
$$

in equilibrium, $t \geq 1$, according to (9) and (11). Moreover, $n^{X}=1-L^{Y} / N^{L}$, according to (4). Thus, the equilibrium share of laborers who work in the $X$-sector in $t \geq 1$ follows the process

$$
n_{t}^{X *}=1-\xi_{t}^{*} l_{t}^{y^{*}}=1-(1-\alpha) A_{t}\left[0.5(1-\alpha)^{2} A_{t}^{2}-\bar{k}\right]
$$

Provided that a steady state exists and is stable, the evolution of the key variables towards the steady state can be characterized as follows. For a given stream of public investment levels $G_{t}, t \geq 1$, let $A\left(G_{t+1}\right)$ be defined by $a\left(n^{E *}, G_{t+1}, A\right)=A$, where

\footnotetext{
${ }^{18} \delta>0$ reflects the notion that there is some depreciation of knowledge over time, as productivity changes according to $\Delta A_{t+1}=\left(n_{t}^{E}\right)^{\gamma} h(G) A_{t}^{\varepsilon}-\delta A_{t}$ (with $\left.\Delta A_{t+1}=A_{t+1}-A_{t}\right) . h(0)>0$ allows productivity progress without public expenditure $G$.

${ }^{19}$ To see this, substitute $n^{E *}=0.5(1-\alpha)^{2} A^{2}$ into (12) and note that the resulting function is strictly concave in $A$ when $2 \gamma+\varepsilon<1$. Moreover, $a\left(n^{E *}, G, A\right)=A$ has a unique solution which gives $A(G)=\left[0.5^{\gamma}(1-\alpha)^{2 \gamma} h(G) / \delta\right]^{1 /(1-2 \gamma-\varepsilon)}$.
} 


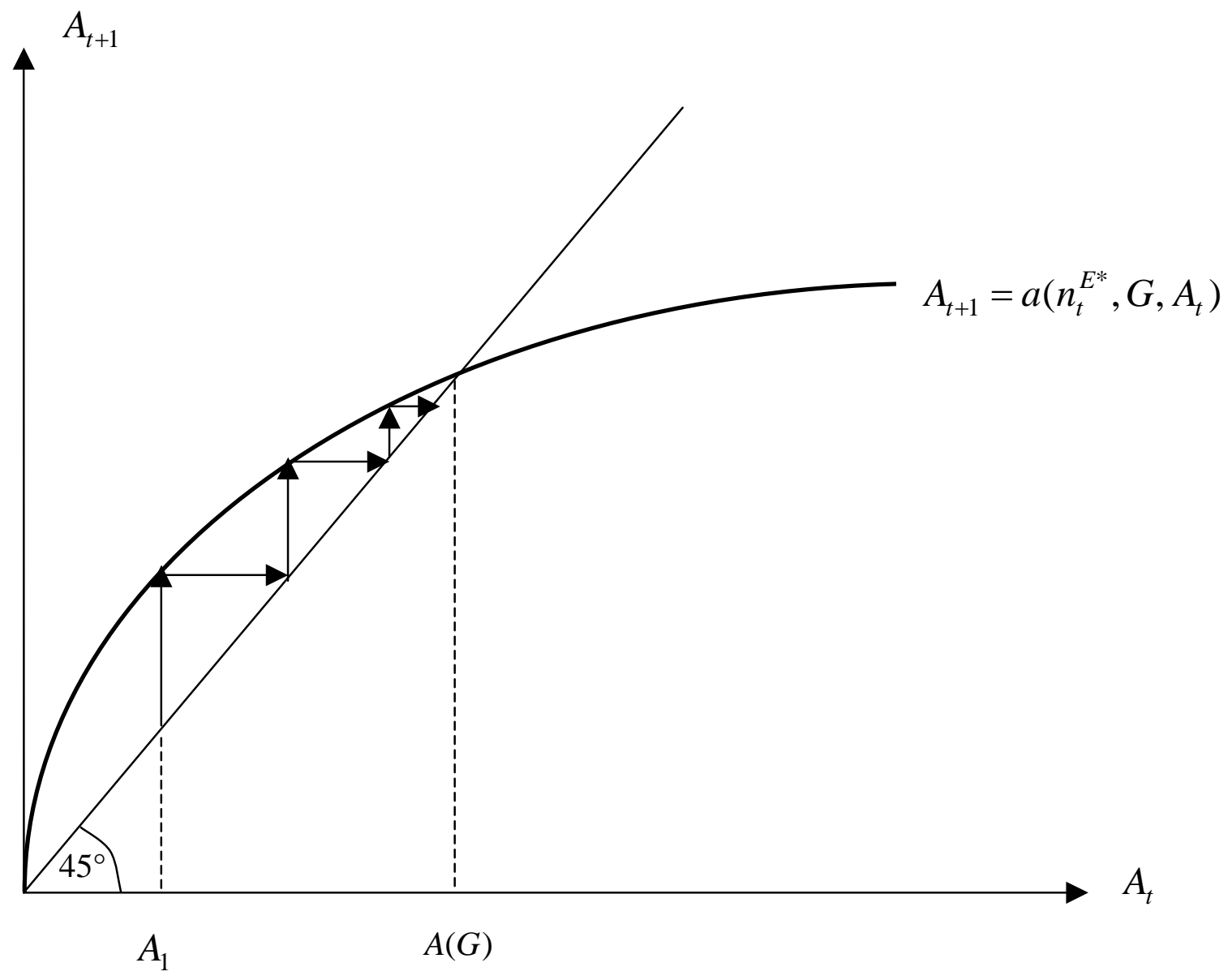

Figure 2: Evolution of total factor productivity in unconstrained regime $\left(G_{t}=G\right)$. 
$n^{E *}=0.5(1-\alpha)^{2} A^{2}-\bar{k}$. As discussed, if $G_{t}$ is constant, $A_{t}$ approaches steady state value $A(G)$. If $G_{t}$ rises over time, productivity approaches $\bar{A}=\lim _{t \rightarrow \infty} A\left(G_{t}\right)$. This has the following economic consequences.

Proposition 1. (Dynamics in unconstrained regime). If $G_{t}$ is non-decreasing over time and $A_{1}<A\left(G_{2}\right)$, then the equilibrium share of entrepreneurs $\left(n^{E *}\right)$, entrepreneurial profits $\left(\pi^{y *}\right)$ and manufacturing output $\left(Y^{*}\right)$ increase over time, along with productivity $A$, whereas both the equilibrium share of laborers in the resource-intensive sector $\left(n^{X *}\right)$ and, if $\vartheta>0$, profits of resource owners $\left(\pi^{x *}\right)$ decrease over time.

Thus, economic development goes along with structural change, in the sense of a reallocation of laborers from the $X$ - to the $Y$-sector. It is characterized by rising entrepreneurship and rising firm sizes in the manufacturing sector $\left(l^{y *}\right)$ over time. In turn, oligopsony power of resource owners and therefore their equilibrium profits, $\pi^{x *}$, decrease (provided $\vartheta>0$ ) and those of entrepreneurs, $\pi^{y *}$, increase over time.

In addition, we have the following comparative-static results for the equilibrium without credit-constraints.

Proposition 2. (Comparative-statics in unconstrained regime).

(i) The distribution of natural resources (captured by $n^{R}$ ) does not affect the equilibrium share of entrepreneurs $\left(n^{E *}\right)$, the share of laborers who work in the $X$-sector $\left(n^{X *}\right)$, entrepreneurial profits $\left(\pi^{y *}\right)$ or manufacturing output $\left(Y^{*}\right)$ in any period.

(ii) An increase in fixed costs $\bar{k}$ lowers $n^{E *}, Y^{*}$ and $\pi^{y *}$, raises $n^{X *}$ and, if $\vartheta>0$, also raises $\pi^{x *}$ in the transition to as well as in steady state.

(iii) An (anticipated) increase in public investment $G_{\hat{t}}$ at time $\hat{t}$ raises $n_{t}^{E *}, Y_{t}^{*}$ and $\pi_{t}^{y *}$, lowers $n_{t}^{X *}$ and, if $\vartheta>0$, also lowers $\pi_{t}^{x *}$ for any $t \geq \hat{t}$ during the transition to the steady state.

We have already seen that in the unconstrained regime the first-period income, $I$, which for laborers who are employed in the $X$-sector depends on $n^{R}$, does not affect the decision of laborers to become entrepreneur. This is because entrepreneurial profits $\left(\pi^{y *}\right)$ are independent of $n^{R}$ if access to credit is unlimited. As a result of an unchanged 
allocation of labor (i.e., $n^{E *}$ and $n^{X *}$ are not affected), also productivity growth and thus manufacturing output $\left(Y_{t}^{*}\right)$ are independent of the distribution of resources. In contrast, an increase in entry barrier $\bar{k}$ reduces profits $\pi^{y *}$ and thereby reduces the share of entrepreneurs in all periods, all other things being equal. In turn, a decrease in $n_{t}^{E *}$ not only affects current manufacturing output $Y_{t}^{*}$ but also future output and profits in the $Y$-sector, by lowering future productivity $A_{t+1}$. This again depresses the share of entrepreneurs. Moreover, note that the share of laborers who work in the $X$-sector, $n_{t}^{X *}$, increases hand in hand with the decline in $n_{t}^{E *}$, due to the interrelation between the share of entrepreneurs and manufacturing productivity. If $\vartheta>0$, the larger number of $X$-workers strengthens the oligopsony position of the resource owners so that their profits $\left(\pi^{x *}\right)$ increase with $\bar{k}$ in all periods (recall Lemma 1 ).

Finally, an increase in the public investment level $G_{t}$ in some period $t$ raises current productivity $A_{t}$. It thereby induces more laborers to become entrepreneurs, hence boosting manufacturing output. Due to the positive interrelation between $n^{E}$ and $A$, a transitory increase in public investment has a long-lasting, positive effect on these variables. For the profits of resource owners, the structural change induced by the rise in $G_{t}$ is harmful, provided $\vartheta>0$, as their oligopsony power declines along with labor supply in the primary goods sector. ${ }^{20}$

\subsection{Constrained Regime}

This subsection shows that, when credit constraints are binding for at least some laborers ("constrained regime") and resource owners have oligopsony power $(\vartheta>0)$, higher inequality of natural resources (lower $n^{R}$ ) is detrimental for economic development. Moreover, we again conduct comparative-static analysis with respect to entry barriers $(\bar{k})$ and public investments $(G)$ as well as with respect to financial development (captured by $\eta$ ).

\footnotetext{
${ }^{20} \mathrm{~A}$ transitory increase of public investments does not affect steady state levels, however. To see this, let $G_{t}=\bar{G}$ as $t \rightarrow \infty$ and note that steady state productivity $\bar{A}$ is given by $a\left(n^{E *}, \bar{G}, A\right)=A$, where $n^{E *}=0.5(1-\alpha)^{2} A^{2}-\bar{k}$. Thus, $\bar{A}$ only depends on public investment in the steady state, not on prior public investment levels.
} 
We first examine the investment choice of entrepreneurs, who work in the primary goods sector in their first period of life. $\eta I_{t-1}^{X}$ is the maximum set up cost such a laborer can incur in $t-1$. When endowed with ability $1-\xi$, a potential entrepreneur solves

$$
\max _{l_{t}^{y}} \pi_{t}^{y}(\xi)=\left\{\left(A_{t}-w_{t}^{Y}\right) l_{t}^{y}-k\left(\xi, l_{t}^{y}\right)\right\} \quad \text { s.t. } \quad \eta I_{t-1}^{X} \geq k\left(\xi, l_{t}^{y}\right)
$$

where $k\left(\xi, l_{t}^{y}\right)$ is specified in (2). Hence, his/her optimal capacity is given by

$$
l_{t}^{y c}=\min \left(\sqrt{2\left(\eta I_{t-1}^{X}-\xi-\bar{k}\right)}, l_{t}^{y *}\right) .
$$

$t \geq 1$. Thus, as long as $l^{y c}<l^{y *}$, (s)he installs more capacity if $I^{X}$ is higher, that is, according to Lemma 1, if resources are more equally distributed (higher $n^{R}$ ) or if the share of laborers in the $X$-sector $\left(n^{X}\right)$ is lower. Moreover, firm size $\left(l^{y c}\right)$ now increases with higher ability of an entrepreneur (lower $\xi$ ) or if the credit market is less imperfect (higher $\eta$ ).

For concreteness, we focus on the situation where credit constraints are always binding for laborers who work in the $X$-sector in their first period of life, but laborers who work in the $Y$-sector are never credit-constrained. Possible reasons for this are that either there is a pronounced earnings gap between sectors $\left(w^{Y} \gg I^{X}\right)$ or laborers who are employed in the $Y$-sector in the first period of life have better access to the credit market than their counterparts in the $X$-sector (for instance, because of more favorable financial structures in urban areas, where entrepreneurs are located, as opposed to rural areas). ${ }^{21}$ We obtain the following result.

Lemma 2. There exists a threshold ability level $\xi_{t}^{c}<\xi_{t}^{*}$ such that a creditconstrained laborer becomes entrepreneur in period $t \geq 1$ if and only if $\xi \leq \xi_{t}^{c}$. $\xi_{t}^{c}$ is increasing in $A_{t}, \eta$ and, if $\vartheta>0$, in $n^{R}$. Moreover, $\xi_{t}^{c}$ is decreasing in $\bar{k}$ and $n_{t-1}^{X}$.

Laborers in the $Y$-sector become entrepreneur if and only if $\xi \leq \xi_{t}^{*}$ holds in $t$.

\footnotetext{
${ }^{21}$ That is, $\eta$ is sector-specific and $\eta^{Y}>\eta^{X}$, where $\eta^{j}$ captures financial constraints for a worker in sector $j=X, Y$. Anyway, main results would be unchanged if also laborers who work in the $Y$-sector or only laborers with relatively low ability would be credit-constrained.
} 
Thus, when a share $n_{t-1}^{X}$ of workers was employed in the $X$-sector in $t-1$, there is a share $\left(1-n_{t-1}^{X}\right) \xi_{t}^{*}$ of laborers who worked in the $Y$-sector in $t-1$ and become entrepreneur in $t$. The respective share of laborers in the $X$-sector is $n_{t-1}^{X} \xi_{t}^{c}$. Hence, in the constrained regime, the share of entrepreneurs in $t \geq 1$ is given by

$$
n_{t}^{E c}=n_{t-1}^{X} \xi_{t}^{c}+\left(1-n_{t-1}^{X}\right) \xi_{t}^{*} \equiv \tilde{n}^{E c}\left(A_{t}, n_{t-1}^{X}, n^{R}, \eta, \bar{k}\right)
$$

The effects of $A_{t}, n^{R}, \eta, \bar{k}$, on $n_{t}^{E c}$ come through $\xi_{t}^{*}$ (see (11)) and $\xi_{t}^{c}$ (see Lemma 2). A change in $n_{t-1}^{X}$ has both a direct impact on $n_{t}^{E c}$ and an indirect impact through $\xi_{t}^{c}$. Equilibrium output per laborer in the manufacturing sector at date $t \geq 1$ can be written as

$$
Y_{t}^{c}=A_{t}\left[n_{t-1}^{X} \int_{0}^{\xi_{t}^{c}} l_{t}^{y c} d \xi+\left(1-n_{t-1}^{X}\right) \xi_{t}^{*} l_{t}^{y *}\right] \equiv \tilde{Y}^{c}\left(A_{t}, n_{t-1}^{X}, n^{R}, \eta, \bar{k}\right)
$$

where the first term in squared brackets is employment per laborer in manufacturing firms founded by credit-constrained entrepreneurs who worked in the $X$-sector in their first period of life and the second term comes from the unconstrained entrepreneurs (who worked in the $Y$-sector). The share of workers in the $X$-sector, $n^{X}=1-$ $L^{Y} / N^{L}=1-Y / A$, evolves over time according to

$$
n_{t}^{X}=1-n_{t-1}^{X} \int_{0}^{\xi_{t}^{c}} l_{t}^{y c} d \xi-\left(1-n_{t-1}^{X}\right) \xi_{t}^{*} l_{t}^{y *} \equiv \tilde{n}^{X}\left(A_{t}, n_{t-1}^{X}, n^{R}, \eta, \bar{k}\right)
$$

$t \geq 1$, starting at $n_{0}^{X}=1-L_{0}^{Y} / N^{L}$. Finally, according to (7) and (17), for any $t \geq 1$, the dynamic process which governs manufacturing productivity can be written as

$$
A_{t+1}=a\left(n_{t}^{E c}, G_{t+1}, A_{t}\right) \equiv \tilde{a}\left(A_{t}, n_{t-1}^{X}, G_{t+1}, n^{R}, \eta, \bar{k}\right)
$$

where $A_{1}=a\left(n_{0}^{E}, G_{1}, A_{0}\right)$ is determined by initial conditions.

System (19) and (20) characterize the development of productivity $(A)$ and employment structure $\left(n^{X}\right)$ as functions of natural resource distribution $\left(n^{R}\right)$, of $G$-policy and of other exogenous policy variables $(\eta, \bar{k})$. The channels through which $n_{t-1}^{X}$ and $A_{t}$ are 
linked to $n_{t}^{E c}$ and $Y_{t}^{c}$ are given by (17) and (18). They describe the emergence of the entrepreneurial class and their role for the development of the manufacturing sector.

The following lemma summarizes the properties of the functions defining system (17)-(20).

Lemma 3. (i) $\tilde{n}^{E c}, \tilde{Y}^{c}$ and $\tilde{a}$ are increasing in $A_{t}$, $\eta$, and, if $\vartheta>0$, in $n^{R}$. They are decreasing in $n_{t-1}^{X}$ and $\bar{k}$. Moreover, $\tilde{a}$ increases with $G_{t+1}$. (ii) $\tilde{n}^{X}$ is decreasing in $A_{t}, \eta$, and, if $\vartheta>0$, in $n^{R}$. It increases with $n_{t-1}^{X}$ and $\bar{k}$.

We are now ready to derive comparative-static results for the transitional dynamics in the constrained regime. (A steady state analysis will follow.)

Proposition 3. (Comparative statics in constrained regime).

(i) If $\vartheta>0$, a more equal distribution of natural resources (higher $n^{R}$ ) raises the share of entrepreneurs $\left(n^{E c}\right)$, manufacturing output $\left(Y^{c}\right)$ and entrepreneurial profits in any period, whereas it reduces both the share of workers in the $X$-sector $\left(n^{X}\right)$ and profits of resource owners.

(ii) Better financial markets (higher $\eta$ ) or a decrease in fixed costs $(\bar{k})$ positively affect $n^{E c}, Y^{c}$ and entrepreneurial profits in any period, while reducing $n^{X}$; moreover, if $\vartheta>0$, profits of resource owners decline.

(iii) An (anticipated) increase in public investment $G_{\hat{t}}$ at time $\hat{t}$ raises $n_{t}^{\text {Ec }}, y_{t}^{c}$ and entrepreneurial profits, while reducing $n_{t}^{X}$ for any $t \geq \hat{t}$ during the transition; moreover, if $\vartheta>0$, it reduces profits of resource owners.

Comparing part (i) of Proposition 3 with part (i) of Proposition 2 reveals a striking difference regarding the impact of higher equality of the resource distribution $\left(n^{R}\right)$ on the development path in the constrained regime, compared to the unconstrained regime. In the constrained regime, higher first-period income $I^{X}$ induced by an increase in $n^{R}$ (provided resource owners exert oligopsony power) allows credit-constrained entrepreneurs to invest an amount which is closer to the optimal level, and thus raises their profits as well as $n^{E c}$ and $Y^{c}$. An increase in $n^{E c}$ has two further effects. First, less workers are remaining in the primary goods sector (i.e., $n^{X}$ declines). This raises their 
wage income further and hence allows for higher investments of credit-constrained entrepreneurs also in the next period. Second, an increase in $n^{E c}$ raises productivity in the subsequent period, which again lowers $n^{X}$. In sum, an increase in $n^{R}$ is conducive for development. Moreover, due to a positive link between $n^{X}$ and $\pi^{x}$ on the one hand and the direct impact of a higher $n^{R}$ on $\pi^{x}$ on the other hand (Lemma 1), an increase in $n^{R}$ lowers profits of each resource owner.

Similar effects arise when $\eta$ increases, which means that credit constraints are ceteris paribus less severe, or when entry barriers $\bar{k}$ decline. An increase in $\eta$ allows higher investments of credit-constrained entrepreneurs, whereas a decrease in $\bar{k}$ raises investments of all entrepreneurs. Hence, profits and thus entrepreneurship are boosted in any period, again implying further effects on future investments by raising productivity and diminishing oligopsony power of resource owners.

Finally, as in the unconstrained regime, an increase in public investment level $G$ raises entrepreneurship by boosting productivity and profits in the manufacturing sector. This triggers positive effects for future productivity. In addition, the implied structural change reduces oligopsony power of resource owners (when $\vartheta>0$ ) which is again conducive to development by easing credit constraints.

We next characterize the dynamic system and the steady state in the constrained regime. According to (19) and (20),

$$
\begin{aligned}
\Delta n_{t}^{X} & =n_{t}^{X}-n_{t-1}^{X}=\tilde{n}^{X}\left(A_{t}, n_{t-1}^{X}, n^{R}, \eta, \bar{k}\right)-n_{t-1}^{X} \\
\Delta A_{t+1} & =A_{t+1}-A_{t}=\tilde{a}\left(A_{t}, n_{t-1}^{X}, G_{t+1}, n^{R}, \eta, \bar{k}\right)-A_{t} .
\end{aligned}
$$

Steady state values are given by $\Delta n^{X}=\Delta A=0$. Fig. 3 shows a locally stable steady state for $G_{t}=G$ in $n^{X}-A$-space. ${ }^{22}$

In the situation of an underdeveloped economy where $n_{0}^{X}>\bar{n}^{X}$ and $A_{1}<\bar{A}$ (i.e., the primary goods sector is large and manufacturing productivity is low initially),

\footnotetext{
${ }^{22}$ In a supplement to this paper, we provide a numerical example of our model which gives rise to the situation in Fig. 3. For this purpose, we adopt specification (12) for function $a$ and assume $f(z)=z^{\beta}, 0<\beta<1$, for function $f$ in (1). We also show that the parameter values in our numerical illustration of Fig. 3 are consistent with all parameter restrictions made in our analysis.
} 


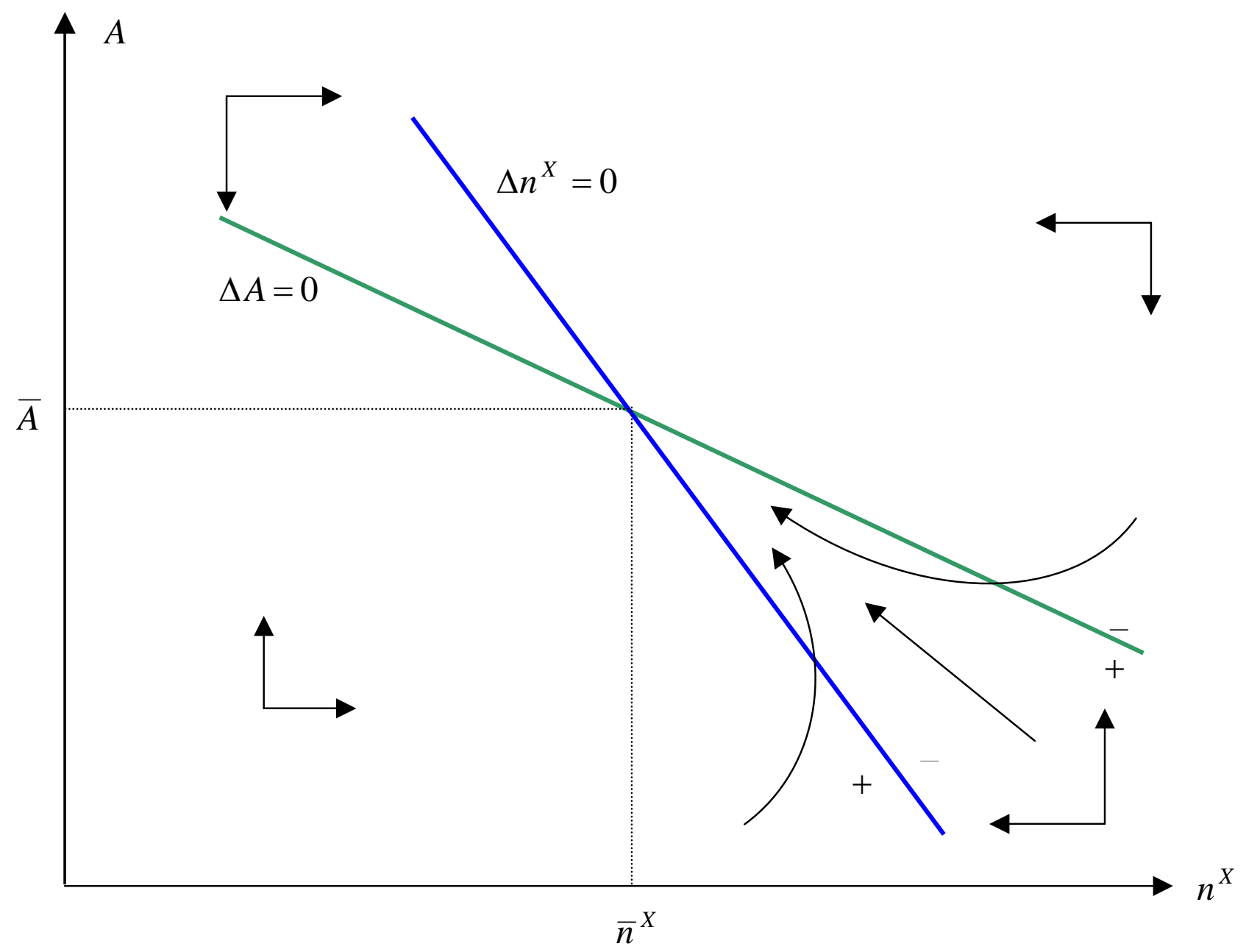

Figure 3: Phase diagram in constrained regime around a locally stable steady state. 
there are three possible transition paths towards a stable steady state, depending on initial conditions. The first scenario applies when starting between the $\Delta n^{X}=0$ and $\Delta A=0$ line in the South-East corner of Fig. 3. Then we have a decline in $n^{X}$ along with increases in productivity $A$ during the entire transition path. In this case, entrepreneurship and manufacturing output always rise over time. In a second scenario, which applies when starting to the right of the $\Delta A=0$ line, the transition path is characterized by a decline in productivity in the early phase of development (when $n^{X}$ is high) and an increase in later phases (when the economy enters the first scenario). The $X$-sector always shrinks over time. In both scenarios, manufacturing employment $L^{Y}$ will always increase over time (recall $n^{X}=1-L^{Y} / N^{L}$ ). Nevertheless, due to initially declining productivity, the share of entrepreneurs and manufacturing output may stagnate in an early transition phase in the second scenario, before taking off later on. The same may happen in the third scenario, which applies when starting below the $\Delta n^{X}=0$ line, but for the opposite reason: The size of the primary goods sector increases in an early phase before declining in mature stages (when the economy enters the region considered in the first scenario). $A$ increases during the entire transition.

Comparative-static results for the steady state are as expected in view of our previous results. Applying Lemma 3 we see that a permanent increase in $G$ shifts the $\Delta A=0$ line in Fig. 3 upwards, which implies an increase in steady state manufacturing productivity, $\bar{A}$, and a decrease in steady state share of workers in the $X$-sector, $\bar{n}^{X}$. This goes along with increases in the share of entrepreneurs, manufacturing output and profits in the $Y$-sector, whereas steady state profits of resource-owners are reduced (provided $\vartheta>0$ ). The same qualitative effects occur when $\eta$ and $n^{R}$ rises (where $\vartheta>0$ is presumed for the latter) or when $\bar{k}$ declines. These changes not only trigger an upward shift of the $\Delta A=0$ line in Fig. 3, but also a leftward shift of the $\Delta n^{X}=0$ line. 


\section{Political Equilibrium}

The preceding analysis has shown that, for given policy variables, a more equal distribution of resources is conducive to development when two conditions are met: first, credit constraints for entrepreneurial investment are binding and second, resource owners have oligopsony power in the labor market. In this section, we examine the role of the distribution of economic resources for policy variables in political equilibrium.

In early stages of development, owners of land and other natural resources form the unchallenged economic and political elite. However, as the economy develops, rising entrepreneurship creates an additional economically powerful class, which may be referred to as "entrepreneurial elite". We assume that political outcomes are solely governed by the interests of these two elite groups. This captures the fact that in earlier stages of development, countries are rarely characterized by democratic rule. For instance, in Latin America after independence, political institutions were usually characterized by severe voting restrictions (like wealth or literacy requirements for gaining citizenship) or lack of secrecy in balloting, as a consequence of the inequality in initial factor endowments (Engerman and Sokoloff, 2002, 2005a,b). Apart from voting restrictions, the interests of economically powerful groups may dominate political outcomes through lobbying, corruption or direct political representation by members of the elites. (See section 7 for further discussion and evidence.)

The two elite groups may in principle have many common interests and nonetheless markedly differ in their policy preferences. As we have seen, the factors which are favorable to development and structural change are raising entrepreneurial profits, but reduce the profits of resource owners by cutting their oligopsony power. This potentially gives rise to a conflict between the traditional elite and the rising entrepreneurial elite. Since the relative economic strength of the two elite groups changes over time, their political weights depend on the stage of economic development. 


\subsection{Public Investments}

We start the political analysis by examining public investment policy. We assume that the implemented spending level in period $t$ is a weighted average of the preferred investment levels of the two elites, where the political weights are equal to the ratio of total profits of an elite to the economy's aggregated profits. This captures the close connection between political and economic power. For simplicity, we assume that political weights are based on past profits. ${ }^{23}$ Whereas the resource owners form a homogenous group in our model, entrepreneurs are heterogeneous with respect to firm size in the constrained regime. The relatively rich group of previous $Y$-workers was not credit-constrained and has larger firms than entrepreneurs from the group of previous $X$-workers who were credit-constrained. We assume that the owners of the larger firms represent the entrepreneurial elite. ${ }^{24}$

Formally, let $G_{t}^{R}$ denote the preferred public investment level in $t$ of the traditional elite and denote by $G_{t}^{E}$ the corresponding level of the entrepreneurial elite. (The two policies will be determined below.) In political equilibrium, the implemented policy is

$$
G_{t}=\frac{\prod_{t-1}^{X} G_{t}^{R}+\Pi_{t-1}^{Y} G_{t}^{E}}{\prod_{t-1}^{X}+\prod_{t-1}^{Y}}
$$

where $\Pi^{X}$ and $\Pi^{Y}$ are total profits of the traditional and entrepreneurial elite, respectively. Public spending is financed by a uniform lump-sum tax on non-resource owners, levied in both periods of life. ${ }^{25}$ That is, in period $t$, each laborer pays a tax $g_{t}=G_{t} / 2$. (Recall that $G$ is investment per laborer.) Uniform lump-sum taxation on individuals born as laborers implies that entrepreneurial decisions are not affected by taxation. ${ }^{26}$

\footnotetext{
${ }^{23}$ That past and not current profits are relevant may reflect some inertia in the political system. The assumption greatly simplifies the analysis. Otherwise, currently implemented policy, affecting current profits, would feed back on the political weights.

${ }^{24}$ Remark 1 in Appendix B assumes alternatively that a credit-constrained entrepreneur with high ability represents the entrepreneurial elite and shows that the main results qualitatively remain the same.

${ }^{25}$ Taxing also resource owners would strengthen our results. An interesting fact in this respect is that in 19th century Latin America, landowners hardly paid any taxes. See, for instance, Centeno (1993) and Sokoloff and Zolt (2004).

${ }^{26}$ Our main results would be unchanged if we would assumed that entrepreneurs pay a different amount of taxes than retired laborers in the second period of life. The occupational choice would be
} 
Although the traditional elite does not pay any taxes, resource-owning households will oppose productive public investments when they have oligopsony power $(\vartheta>0)$. This holds irrespective of whether or not potential entrepreneurs face credit constraints. To see this, consider the decision of a resource-owner born in $t$. A decision in $t$ to support a higher $G_{t}$ would not affect the share of workers who seek employment in the $X$-sector in $t, n_{t}^{X}$, as entrepreneurial decisions have already been made. However, an increase in $G_{t}$ would boost manufacturing productivity $A_{t}$ and thus also $A_{t+1}$. A young resource owner anticipates that this would decrease the share of workers supplying labor to the primary sector, $n_{t+1}^{X}$, which in turn reduces oligopsony power and therefore profits in $t+1$ (the second period of life). Hence, if $\vartheta>0$, then $G_{t}^{R}=0$ at all times. (When $\vartheta=0$, resource owners are indifferent with respect to $G$.)

The preferences of the entrepreneurial elite, represented by an agent who was not credit-constrained, are different. Using profit function (10) together with relationship (7), and observing $g_{t}=G_{t} / 2$, we find that the preferred public investment level of the entrepreneurial elite in $t \geq 1$ is given by

$$
G_{t}^{E}=\arg \max _{G_{t} \geq 0}\left\{0.5(1-\alpha)^{2} a\left(n_{t-1}^{E}, G_{t}, A_{t-1}\right)^{2}-\xi-\bar{k}-0.5 G_{t}\right\}
$$

For the analysis of preferred spending levels of entrepreneurs, we make the following additional assumptions. First, we focus on interior solutions for $G_{t}^{E}$. This requires that function $a$ in (7), which relates $G$ to manufacturing productivity, is sufficiently concave as function of $G$. (That is, in specification (12), function $h(G)$ is sufficiently concave.) Second, we assume that cross derivatives $\partial^{2} a / \partial G \partial n^{E}$ and $\partial^{2} a / \partial G \partial A$ are non-negative (as in (12)), which means that public investment is not less effective in raising productivity in more advanced economies. It is easy to see that under these assumptions $G_{t}^{E}$ is positively linked to the stage of development (characterized by $n_{t-1}^{E}$ and $\left.A_{t-1}\right)$. Also, $G_{t}^{E}$ is independent of $\xi$.

Let us denote the public investment levels in political equilibrium in the unconstrained and constrained regime by $G_{t}^{*}$ and $G_{t}^{c}$, respectively. It is easy to see that the altered in a straightforward way by a differential tax treatment, without providing further insights. 
equilibrium investment levels for period 1 are determined by initial conditions only, and $G_{1}^{*}=G_{1}^{c}$. For $t>1$, we have the following results.

Proposition 4. (Public investment in political equilibrium).

(i) If $\vartheta>0$, a more equal distribution of natural resources (higher $n^{R}$ ) raises both $G_{t}^{*}$ and $G_{t}^{c}$, where the impact of a change in $n^{R}$ on $G_{t}^{c}$ is larger than that on $G_{t}^{*}$, all other things equal. Moreover, an increase in entry barriers (higher $\bar{k}$ ) lowers both $G_{t}^{*}$ and $G_{t}^{c}$; better financial markets (higher $\eta$ ) positively affect $G_{t}^{c} \cdot{ }^{27}$

(ii) Suppose that initial conditions are such that, for a time-invariant public spending level $G_{t}=G$, manufacturing productivity (A) increases and the share of workers in the $X$-sector $\left(n^{X}\right)$ decreases over time. Then both $G_{t}^{*}$ and $G_{t}^{c}$ are increasing over time in the transition to a steady state.

(iii) For any set of initial conditions, $G_{t}^{*}>G_{t}^{c}$.

The first result in Proposition 4 together with part (iii) of Proposition 2 implies that, even in the unconstrained regime, a more equal distribution of natural resources promotes economic development through higher public investments $G_{t}^{*}$ in political equilibrium, although a change in $n^{R}$ has no direct economic effect on development when taking economic policy as exogenous (part (i) of Proposition 2). This is because the exploitative power of resource owners in the labor market (when $\vartheta>0$ ) declines and the profit per owner $\left(\pi^{x}\right)$ shrinks more than proportionally when the number of owners (or $n^{R}$ ) increases. As a consequence, total profits of resource owners $\left(\Pi^{X}\right)$, and therefore their political power, are decreasing in $n^{R}$.

In the constrained regime, the positive impact of an increase in $n^{R}$ on public spending is higher than in the unconstrained regime. The reason is that in the constrained regime an increase in $n^{R}$ has a direct positive effect on structural change and economic development (Proposition 3, part (i)). This has two consequences. First, an increase in $n^{R}$ induces a more pronounced shift in political power from the traditional to the entrepreneurial elite in the constrained regime. Second, an increase in $n^{R}$ has a larger

\footnotetext{
${ }^{27}$ By definition, $\eta$ plays no role in the unconstrained regime.
} 
effect on the preferred public investment level of the entrepreneurial elite $\left(G^{E}\right)$ since $G^{E}$ is positively linked to the stage of development.

Entry barriers are an impediment for structural change and development, irrespective of whether or not credit constraints play a role. In the constrained regime, also financial development affects growth. Since the political weight of the entrepreneurial elite vis-à-vis resource owners as well as their preferred public investment level, $G^{E}$, positively depends on the stage of development, a decrease in $\bar{k}$ or (in the constrained regime) an increase in $\eta$ raises $G$ in political equilibrium.

Part (ii) of Proposition 4 implies that there is a positive feedback loop from economic development to public investment and further development. Suppose that we start in the first scenario discussed in section 4 . That means, the economy has reached the stage of development corresponding to the South-East corner in Fig. 3. Then, the economy develops also for a given public investment level. Over time, the distribution of profits, and consequently the distribution of political power changes in favor of the entrepreneurial elite. Moreover, $G^{E}$ is rising over time. Hence, economic development triggers an increase of public investment in political equilibrium, which in turn leads to faster growth during the transition to a steady state.

Finally, according to part (iii) of Proposition 4, since credit constraints are an obstacle to structural change and economic development by impeding entrepreneurship, productive public spending in political equilibrium is higher in the unconstrained regime $\left(G_{t}^{*}>G_{t}^{c}\right)$, all other things being equal.

\subsection{Institutions}

The second parts of Propositions 2 and 3 imply that lower entry costs $\bar{k}$ and, in the constrained regime, better access to credit (higher $\eta$ ) are conducive to development by promoting entrepreneurship. Both entry barriers and financial development depend on the institutional structure of an economy and thus, on the political will of the elites.

Suppose that feasible values of $\bar{k}$ and $\eta$ are given by some closed intervals $\left[\bar{k}^{0}, \bar{k}^{1}\right]$ and $\left[\eta^{0}, \eta^{1}\right]$, respectively, with $\bar{k}^{0} \geq 0$ and $\eta^{0} \geq 1$. Clearly, in view of the results 
of Proposition 2 and 3 on $\pi^{x}$, resource owners favor entry barriers to be as high as possible, i.e., $\bar{k}=\bar{k}^{1}$, and object any development of credit markets, which means $\eta=\eta^{0}$. Traditional elites show an aversion towards institutions which are conducive to entrepreneurship.

Policy preferences of entrepreneurs are more subtle. If all costs of setting up a manufacturing firm would literally accrue before production starts, an entrepreneur would be indifferent regarding the level of $\bar{k}$ and $\eta$ at the time at which (s)he produces and has political power. However, this may not be fully realistic. Suppose, for instance, that an entrepreneur has to incur some part of fixed costs at a later point of time (e.g., has to bribe a bureaucrat in order to stay in business). Then (s)he would be in favor of the lowest possible $\bar{k}$ (e.g., no corruption or well defined property rights) which is given by $\bar{k}^{0}$. Similarly, to finance these costs, (s)he would prefer low credit constraints (in the constrained regime). In such a case, policy preferences of the entrepreneurial elite regarding $\bar{k}$ and $\eta$ are diametrically opposed to those of the traditional elite. If the political outcome is again a weighted average of the policy preferences of the two elites, then we have an analogous result to part (i) of Proposition 4.

Proposition 5. (Resource distribution and institutions in political equilibrium). A more equal distribution of natural resources (higher $n^{R}$ ), leads to lower institutional entry barriers $(\bar{k})$ and better financial markets (higher $\eta$ ) in political equilibrium, all other things equal.

Since the entrepreneurial elite gains political weight as the economy develops, our analysis also predicts that the institutional environment improves $(\bar{k}$ declines and $\eta$ increases) over time.

\section{Resource Distribution and Development}

As a corollary to the first parts of Propositions 2-4 and Proposition 5, combining the economic and political role of inequality, we can state: 
Theorem 1. Under oligopsony power of resource owners in the labor market, economic development and structural change is faster when the distribution of economic resources is more equal. In the constrained regime, this result holds also for given policy variables and is reinforced through the political channel. In the unconstrained regime, the result is exclusively driven by the political channel.

Theorem 1 summarizes the results on the relationship between the distribution of natural resources and economic development implied by our theory. Fig. 4 provides a graphical representation of the main mechanisms. The economic channel is represented by the left side and the additional channel through endogenous public investment is shown on the right side of the diagram.

First, the left side of Fig. 4 shows that the distribution of resources affects wage income of workers in the primary goods sector through its effect on oligopsony power of resource owners. In turn, provided that credit constraints for entrepreneurial investments are binding for these workers, the resulting wage income in $t-1$ determines their capability to create a profitable manufacturing firm and thus their incentives to act as entrepreneur in $t$. Entrepreneurship in $t$ then determines the allocation of labor across sectors in $t$. In turn, the share of workers in the primary goods sector in $t$ affects oligopsony power of resource owners and thereby determines wage income in $t$, which again affects entrepreneurship in the presence of credit constraints. Moreover, a higher share of entrepreneurs in $t$ positively affects manufacturing productivity in $t+1$, which in turn raises entrepreneurial profits and therefore again boosts entrepreneurship in $t+1$.

The right side of Fig. 4 shows that the distribution of natural resources, by affecting the distribution of profits among the two elites, determines public investments in political equilibrium. This reflects the assumption that the political outcome hinges on the distribution of economic power, as the latter is directly linked to the distribution of political power. Public spending boosts manufacturing productivity in our model which in turn raises incentives for entrepreneurial investment and therefore is conducive for development. Positive public spending is politically supported by entre- 


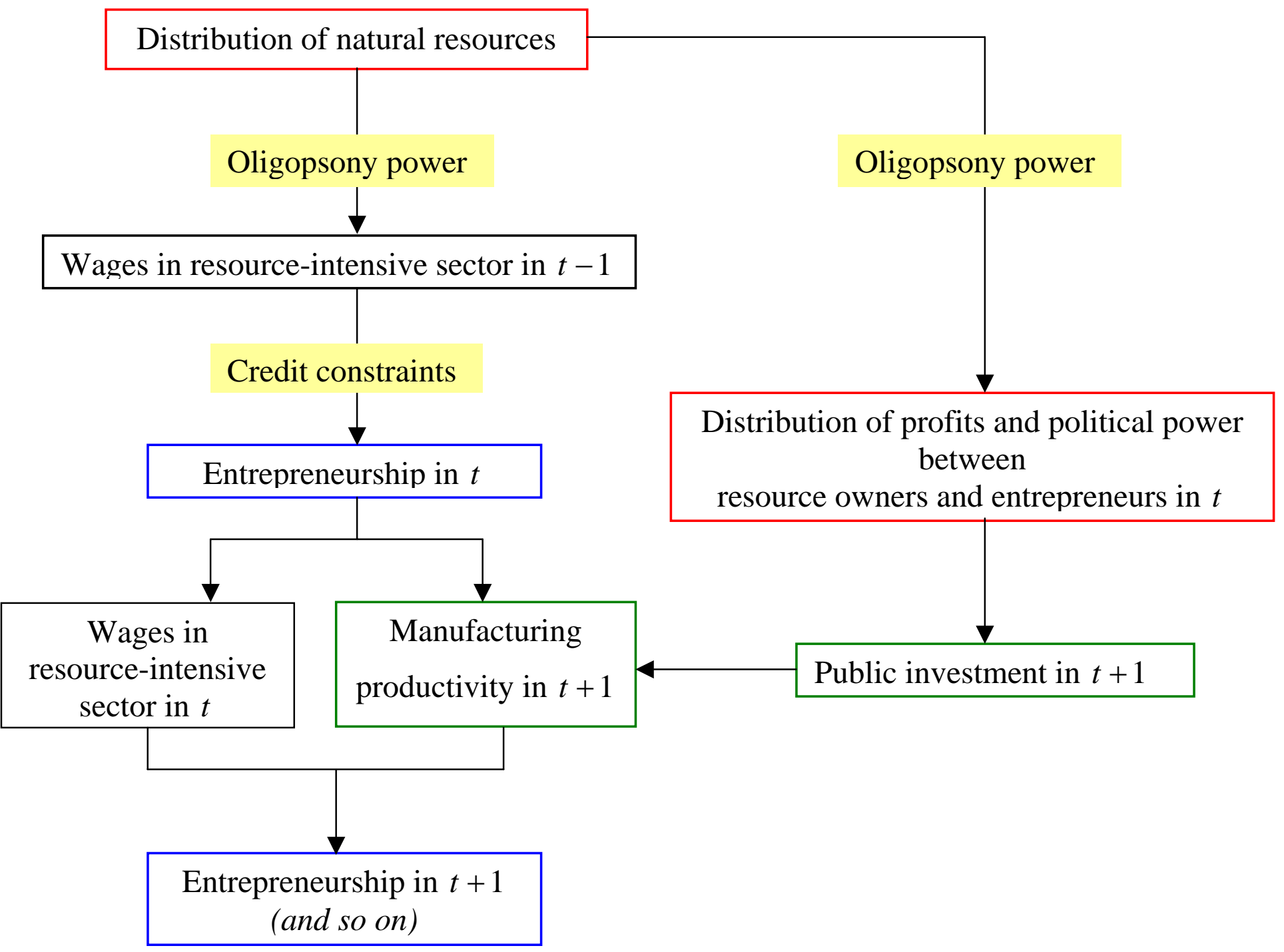

Figure 4: Resource distribution and development. 
preneurs - where the preferred spending level depends on the stage of development but opposed by the traditional elite at all times even though their tax share is zero. To sum up the political channel, higher equality of the resource distribution implies a higher level of public spending in political equilibrium, which positively affects the speed of development. Moreover, faster development has a positive feedback effect on the equilibrium level of public investment. An analogous virtuous circle applies to institutional progress lowering entry costs or credit-constraints.

\section{$7 \quad$ Evidence}

Our analysis strongly suggests that the differential patterns between North and South America with respect to structural change, industrialization and economic policy, as outlined in section 1, have their roots in extreme differences in the distribution of natural resources across regions in the Americas - inherited from the colonization period - and the associated biases in the distribution of political power. This section demonstrates that the main hypotheses proposed by our theory on how the resource distribution shapes structural change, entrepreneurship, economic policy and development are well-supported empirically. While mainly focussing on evidence for the Americas in the nineteenth and the first half of twentieth century (section 7.1), we also argue that our theory is consistent with patterns in other regions (and at other times), like in today's transition economies (section 7.2).

\subsection{The Case of the Americas}

In this subsection, we will first provide evidence for the Americas on the economic mechanisms that in our framework establish a link between labor market power of resource owners and development of the manufacturing sector. We then turn to the suggested relationship between resource distribution and the policy variables public education, infrastructure and the institutional environment. 


\subsubsection{Economic Channel}

Roots of Land Inequality Basically irrespective of colonial origin, the predominant colonial heritage in Latin America after independence was the extreme inequality in landholdings, as outlined in section 1, and the associated political power of the landed aristocracy (e.g., Mosk, 1951; Morse, 1975, Engerman and Sokoloff, 2002, 2005). ${ }^{28}$ This is true although total land holding in the eve of independence was only a fraction of the employed land in the first half of the twentieth century. During the nineteenth century, thanks to booming demand for agricultural goods from the world market, large areas of former crown land was sold or granted. However, rather than alleviating the existing inequalities, new land was typically distributed in a way that massively aggravated the inherited land concentration. For instance, land was offered for sale in huge parcels which only wealthy landownwers, mineowners or merchants, with sufficient access to credit, could afford (Bulmer-Thomas, 1994; Schweigert, 2004). The same is true for the massive privatization of land, which has long been held communally, in the second half of the nineteenth century. ${ }^{29}$ Rising concentration of landownership was also in part the result of conquest; governments granted outright gifts to followers and contributors to military operations, like in the Indian wars in Argentina, Chile and Mexico at the end of the nineteenth century (Mosk, 1951; Katz, 1974; Morse, 1975; Bulmer-Thomas, 1994).

Oligopsony Power In sum, colonial heritage had long-lasting effects on the land distribution. The result was a substantial degree of power of big landowners in the labor market for rural work, characterized by exploitation and oppression, and often

\footnotetext{
${ }^{28}$ As pointed out by Bulmer-Thomas (1994, p. 94), "in some counties, such as Paraguay after 1870, the overlap between the state and the landowning class was so great to render meaningless any attempt to distinguish between them analytically". In a similar vein, Pregger-Román (1983) reports that in the period 1849-52, 62.5 percent of legislators in the Chilian congress were central-valley latifundistas and 7.8 percent were wealthy merchants who primarily sold foreign manufacturing goods to big landowners.

${ }^{29}$ The result was that most Indian villages, formerly characterized by a system of smallholding, were stripped off their customary lands. As Bulmer-Thomas (1994, p. 94) points out: "Many of the huge estates in El Salvador and Guatemala, for example, owe their origin to the alienation of communal land after 1870."
} 
sustained by debt peonage and other kinds of informal labor coercion. ${ }^{30}$ According to Bauer (1979, p. 36f.), "peonage became a general practice in nineteenth century Mexico. [...] The combination of strong markets for tropical exports (sisal, rubber, sugar), a labor shortage, geographical isolation, and a progressive state willing to support the planters with force explains the virtual enslavement of masses of Mayas and Yaquis". ${ }^{31}$ Similarly, in Bolivia, about "two-thirds of the rural population became dependent upon haciendas" (Bauer, 1979, p. 56). In Guatemala, "between 1871 and 1944 a substantial amount of labour was reallocated, in part through state-enforced coercion, from the more subsistence-oriented peasant economy to the commercial agricultural sector of large coffee plantations" (Schweigert, 2004, p. 532f.). ${ }^{32}$ As a result, according to Schweigert (2004, Tab. 5), the real wage rate for agricultural labor in Guatemala was extremely low and showed no upward trend in the century prior to the revolution in 1944.

In other regions of Spanish America like Peru or Argentina direct or informal labor coercion was less common or even absent (Bauer, 1979). Although big landowners undoubtedly possessed labor market power, they competed for labor within certain limits. Moreover, due to some smallholdings in the workers' villages, labor supply was not fully inelastic. ${ }^{33}$ Some competition also came from the rising demand of labor in mines in some regions, like in Chile. (However, the emerging class of rich mine owners colluded politically with the agricultural bourgeoisie and latifundistas). In

\footnotetext{
${ }^{30}$ Morse (1975, p. 8) concludes: "Consolidation of agricultural holdings during the century gave displaced farm workers few choices; most remained in the rural sector as peons."

${ }^{31}$ The poor village and smallholder population accepted to work on the plantations in return to cash advances and had to stay until the debt was paid off. Debt repayment was difficult, however. Employers operated company stores where goods were sold at inflated prices. This contributed to a stagnation of real wages for many decades. After death, the duty to repay debt was passed on to children. (See Katz, 1974, and Bulmer-Thomas, 1994, ch. 4.) As the 93th conference of the International Labour Organization, held in Geneva in June 2005 has pointed out, this kind of debt bondage and forced labor is even today frequently detected, at fairly large scale, by government inspectors on Brazilian farms.

${ }^{32}$ In addition, vagrancy law in Guatemala which replaced debt peonage in 1934 (abandoned in response to international pressure) kept the elasticity of labor supply low by implying that someone with little or no land had to work at least 150 days per year on a coffee plantation.

${ }^{33}$ According to Bauer (1979, p. 58): "In the 1880s in Chile [...] workers even during harvest season rarely worked more than twenty days of the month." Also in Mexico, where labor coercion was perhaps most present, landowners in the North were forced to moderately raise wages in face of competition from the U.S. industry (Katz, 1974).
} 
sum, consistent with our model, an unequal distribution of land and other natural resources like minerals was associated with substantial oligopsony power in the labor market, albeit to varying degree. Additional support for this hypothesis is provided by Wright (1987, Fig. 1) who points to regional differences within the United States. By providing data for farm labor wage rates for the period 1866-1942, he finds large and persistent regional wage differentials between the South - which was characterized by large plantations - and the rest of the country. ${ }^{34}$

Industrialization Consistent with our theory, the combination of oligopsony power of landowners and credit market imperfections in Latin America resulted in a slowgrowing manufacturing sector, ${ }^{35}$ which primarily consisted of small establishments, ${ }^{36}$ mostly located in urban areas. ${ }^{37}$ In contrast to modern manufacturing in North America, manufacturing entrepreneurs specialized on handicrafts like processed foods, textiles, shoes, candles, soap etc. ${ }^{38}$

Until the last quarter of the nineteenth century, industrial development was in fact negligible. During the first half of the twentieth century the situation eventually improved, although manufacturing development still lagged considerably behind most regions of North America. Manufacturing output as share of GDP in 1913 was 16.6 percent in Argentina and 14.5 percent in Chile (Bulmer-Thomas, 1994, Tab. 5.3). Mexico, with 12.3 percent in 1910 had a comparable manufacturing share, whereas that

\footnotetext{
${ }^{34}$ As outlined in the next subsection, in the South of the U.S. politicians basically represented the landed elite, trying to secure the strong oligopsony power in the labor market similarly (though not as extreme) as in Latin America.

${ }^{35}$ Consistent with our assumptions, labor was basically the only input in current manufacturing production and, in contrast to the agricultural or mining sector, typically decently remunerated. Typically, workers organized in craft guilds (see Bulmer-Thomas, 1994, p. 121).

${ }^{36}$ In 1939, the average number of workers per establishment in Latin American countries ranged between 10 and 30 (Bulmer-Thomas, 1994, Tab. 7.7).

${ }^{37}$ Unsurprisingly, also urbanization was much slower than in the United States. In Argentina, Chile, Mexico and Uruguay, for instance, the fraction of the national population living in the largest cities basically stagnated in the entire nineteenth century (e.g., around 10 percent in Mexico). In the U.S. the population share residing in towns of 8000 or more inhabitants gradually rose from 4.9 percent in 1810 to 33 percent in 1900 (Morse, 1975, pp. 5-9).

${ }^{38}$ According to Morse (1975, p. 9): "After 1880 industrialization created new groups of workers, mechanics, and white-collar collar employees, but most urban occupations registered in 1900 already existed in 1800."
} 
of Columbia was just 6.7 percent in 1925. In Brazil in 1920 it was 12.1 percent, but only 3 percent of the labor force was employed in modern manufacturing. In the 1930s, annual growth rates of manufacturing output ranged from about 5 percent in Uruguay to almost 12 percent in Columbia and Mexico (Bulmer-Thomas, 1994, Tab. 7.7). In the period of world war II, net manufacturing output grew on 5.7 percent on average (and almost 10 percent in Chile, Mexico and Venezuela), whereas the agricultural sector was stagnant everywhere (Bulmer-Thomas, 1994, Tab. 8.2).

\subsubsection{Political Channels}

Bulmer-Thomas (1994) discusses possible reasons for the slow structural change in Latin America and concludes: "The problems of low productivity in the industrial sector could be traced to shortages of electric power, lack of skilled labor, restricted access to credit, and use of antiquated machinery" (p. 228). 39 This raises the question why economic policy in Latin America (and also in the South of the U.S. which considerably lagged behind the North and West) has not been more conducive for development of the manufacturing sector. The evidence supports our hypothesis of a continued struggle between the traditional elite, which opposed growth-promoting reforms, and the emerging class of entrepreneurs which were in favor of such policies.

Although nominally democracies, political institutions in Latin America were heavily biased towards economic elites. Often well into the twentieth century, they were characterized by wealth and literacy requirements for voting as well as a lack of secrecy in balloting (Sokoloff and Engerman, 2000, Engerman, Haber and Sokoloff, 2000). In view of the huge inequality of land and low literacy rates, ${ }^{40}$ it is not surprising that this

\footnotetext{
${ }^{39}$ That, for instance, (primary) education was highly conducive for development in the nineteenth century is out of question. See e.g. Nichols (1956), Field (1979), Easterlin (1981), and Galor and Moav (2006) for discussions and evidence on the importance of education for industrial development. Evidence by Rosenberg and Trajtenberg (2001) suggests that the adoption of the Corliss steam engine, a prime example of a general purpose technology in the late nineteenth century, not only played a salient role in the industrialization process of the U.S. but also was crucially affected by the regional availability of skill. Pregger-Román (1983) reports for Chile that at the end of the 19th century newspapers frequently complained that employees in artisan industries lacked sufficient skill.

${ }^{40}$ For instance, in 1900, literacy rates in Bolivia, Brazil and Mexico have been 17, 22 and 26 percent, respectively. Higher literacy rates could be found in Argentina, Chile, Cuba and Uruguay, with 52, 43, 40 and 54 percent, respectively (Engerman and Sokoloff, 2005, Tab. 2).
} 
resulted in very low voting participation rates. ${ }^{41}$ The U.S., by contrast, did not have any such restrictions already in mid-nineteenth century and had considerably higher voting participation. ${ }^{42}$

Public investments Consistent with the political analysis in section 5, the attitude of the landed oligarchs in Latin America towards infrastructure and education may best be summarized by the following quote from Mellafe (1971, p. 11): "The owners of great haciendas were opposed to just about everything: to the installation of the telegraph, to electric power, to having a rural police force, to public schooling in rural areas, etc." According to our theory, the main reason for this resistance was that policies conducive to entrepreneurship and structural change would have endangered the oligopsony power of traditional elites in the labor market.

Attempts of federal governments in the second half of the nineteenth century to promote industrialization even resulted in revolutions or civil wars orchestrated by the landed oligarchs. For instance, in Columbia, the federal government published the "Organic Decree of Public Primary Instruction" of November 1, 1870, as a first attempt to implement a centralized primary education system, with mandatory schooling for all children aged 6-14. The opposition of conservatives, however, eventually "contributed to the outbreak of the Civil War 1876-77" (Loy, 1971, p. 275), and any attempts to revitalize schools in the aftermath remained unsuccessful. A similar situation has arisen in Chile, which until 1880 was ruled by an alliance of the traditional land oligarchy together with the agrarian and mining bourgeoisie, whereas "the nascent industrial bourgeoisie was excluded from that alliance" (Pregger-Román, 1983, p. 50). The newly elected President Balmaceda, although coming from a rich landowning family in the central valley, was nevertheless committed to support the emerging industrial interests and "applied much of the government's revenue to public works aimed at improving

\footnotetext{
${ }^{41}$ Sokoloff and Engerman (2000) report the proportion of the population voting for three Latin American countries in the second half of the nineteenth century. It was 1.6 percent in Chile in 1869, 0.1 percent in Ecuador in 1856 and 7.7 percent in Venezuela in 1880. Also in Buenos Aires, only 1.8 percent voted in 1896.

${ }^{42}$ Later on, some states in the U.S. introduced a literacy requirement. However, the literacy rate was already 80 percent in 1870 and 92 percent in 1910 (Engerman and Sokoloff, 2005, Tab. 2).
} 
the nation's infrastructure" (Pregger-Román, 1983, p. 53). This determined his fate. According to Pregger-Román (1983, p. 53): "These economic policies threatened the dependent bourgeoisie as well as the British patrons and led to the political crises that culminated in the revolution of 1891." ${ }^{43}$

In Jamaica, the British Colonial Office attempted to promote schooling in 1870, which was, however, successfully opposed by Jamaican plantocrats who, consistent with our theory, "felt it to be a potential negative force vis-à-vis their own interest in cheap, docile labor" (Keith, 1978, p. 40). In Peru, "local mestizo resistance was sufficient to overwhelm most Indian attempts to form private schools [...] Indian teachers were imprisoned and intimidated, as were those who would seek education. As the Indian drive for instruction became stronger, school buildings were burned, and an active propaganda campaign alleged that popular instruction was synonymous with subversion and anarchy" (Hazan, 1978, p. 428f.).

As already stressed by North (1961, pp. 133f.), also in Southern plantation states in the U.S., "expenditures to educate the large percentage of white southerners who were outside the plantation system was something [the dominant planter class] vigorously opposed". ${ }^{44}$ According to Wright (1987), the main motivation of landowners to oppose policies conducive to industrialization was to secure labor market power. "Cotton mill managers knew that a high school diploma was a good ticket to leave the mill village. [...] But even in state and regional coalitions, Southern employers were not poised to benefit from increased education levels. [...] Southern Democrats were extremely powerful in Congress during the 1930s but [...] although the South was the poorest region in the country it stood last among the regions in per capita federal expenditure between 1933 and 1939" (Wright, 1987, p. 170; italics original).

In Latin America, also railway construction, although important for planters to

\footnotetext{
${ }^{43}$ British residents in Chile were often heavily engaged in the Chilean nitrate sector and had similar interests as the traditional elite. This is underlined by the fact that the "managers and superintendents of the English nitrate oficinas in Tarapacá urged their workmen to join the revolutionists" (U.S. State Department, Dimplomatic Dispatches from Chile, March 17, 1891).

${ }^{44} \mathrm{As}$ a result, in late nineteenth century the average school days per child in the plantation South of the U.S. was less than half of what it has been in Non-Southern states, and literacy rates were significantly lower (Gerber, 1991).
} 
bring their goods to harbors for export, did not get political support by landowners in general. In Brazil, the railway system reflected the influence by powerful "commercial associations", business interest groups which claimed to speak for all business men but effectively only promoted agriculture. ${ }^{45}$ The goal of commercial associations was to reap the benefits from railways without promoting industrialization. As a result, "railways radiated from each port to its tributary hinterland, with few connections between networks or lateral lines which would have helped integrate the nation's economy and stimulate internal commerce" (Ridings, 1977, p. 240). The length of railway track per 1000 population in 1913 was one kilometer in Brazil - of the same order of magnitude as the Latin American average (1.4 kilometers) - as opposed to 6.5 kilometers in Canada (Bulmer-Thomas, 1994, Tab. 4.4). ${ }^{46}$

Credit Market Another important feature of our theory is the relationship between credit restrictions and entrepreneurship in the manufacturing sector. Indeed, the financial sector in Latin America was dramatically underdeveloped. For instance, Bulmer-Thomas (1994, Tab. 4.2) reports that bank deposits per head had been less than US\$ 30 (and often considerably less than \$10) in most of Latin America in circa 1913 (with the exception of Argentina, where the figure was $\$ 76),{ }^{47}$ in contrast to $\$ 143$ in Canada. Moreover, in Latin America "banking rules did not favor the long-term loans the industry needed, and many banks continued to favor the primary exports" (Bulmer-Thomas, 1994, p. 133). There is some indication that, consistent with our theory, traditional elites were influencing the banking system to stifle entrepreneurship. In Chile, according to Pregger-Román (1983, p. 45), "the central-valley hacendados [who] were also creditors [...] used their power in government to forestall reform of the banking mechanism and thereby maintained both the internal dependence structure

\footnotetext{
${ }^{45}$ Consistent with the interests of the traditional elite in our model, Ridings (1977, p. 242) points out: "Commercial associations tended to dislike industry because it competed [...] with agriculture for manpower."

${ }^{46}$ Only Argentina, with 4.3 kilometers of railway track per 1000 population, was comparable with North America in this respect.

${ }^{47}$ In Bolivia, Ecuador, Guatemala, Paraguay and Venezuela, the figure was between $\$ 1$ and $\$ 3$. Typically, successful Latin American businesses relied on family networks for financing new ventures.
} 
and the political alliance that governed the nation".

Shift in Political Power and Economic Policy Over time, however, and as predicted by our model, the emerging entrepreneurial class gained political power and was increasingly successful to implement policy reforms conducive to entrepreneurship, with positive feedback effects on structural change and development. Reimers (2001) points out that education policies and outcomes in terms of literacy gradually improved throughout the first half of the twentieth century in Latin America. Consistent with our theory, landed elites however opposed public education during the entire period, and "struggles between liberals and conservatives continued with the conservatives loosely representing the interests of the landed oligarchies under attack by the emergent industrialists" (Reimers, 2004, p. 10). Industrial interest groups formed and gained power throughout Latin America. In Brazil, for instance, although the "ascendancy of both the traditional economy and the commercial associations was not broken until well into the twentieth century [...] they began to be seriously challenged in the last quarter of the nineteenth century" (Ridings, 1977, p. 245f.). The shift in political power towards industrial interests implied that "industrialization was also stimulated by [...] policies of easy credit" (p. 247), again consistent with our analysis.

\subsection{Transition Economies}

Can we generalize our arguments beyond the Americas, and for more recent growth experiences? Similarly to the colonial heritage of the Americas, the fall of the iron curtain provides us with a quasi-natural experiment. Privatization in transition economies has led to an extreme ownership concentration of natural resources. Consistent with our analysis, there is some first evidence that natural resources - through political power of the newly emerged elite of resource owners - play an important role for ex-

plaining differences in economic development, education investments and institutions across transition countries.

Kronenberg (2004) shows that the share of primary goods exports in GDP - a 
commonly used measure of resource abundance - is positively related to the level of corruption (affecting entry costs to run a business) and negatively related to enrollment rates in basic education. Both variables have substantial growth effects in his sample. In a similar fashion, Beck and Laeven (2005) show that a higher initial export share of natural resources in GDP has substantial negative effects on executive constraints and other indicators of institutional quality, which in turn critically affects subsequent economic growth. ${ }^{48}$ At the same time, the distribution of natural resources is very unequal in resource-abundant transition economies. For instance, in Russia (famous for its "robber barons"), the sales share of the four largest owners in the sectors oil and natural gas (the two largest sectors in Russia) is 59 and 94 percent, respectively (Guriev and Rachinsky, 2004, Tab. 3). The evidence on the adverse effects of resourceabundancy is therefore consistent with the political channel suggested by our analysis.

Another important fact which supports our theory is the salient role of small-scale entrepreneurship for economic growth in transition economies. In their literature survey on the role of entrepreneurs in transition countries, McMillan and Woodruff (2002, p. 166) stress that "New firms have usually been the fastest growing segment in transition economies", compared to privatized firms. For instance, they report that about one-sixth of industrial workers in Poland in 1994 were employed in start up firms. In Estonia, start-ups created almost all new jobs between 1989-94 and more than half of the new jobs in Bulgaria and Romania. ${ }^{49}$ Also in line with our model, credit constraints and entry costs seem to be very important obstacles for entrepreneurship. Earle and Sakova (2000) report that pre-transition income and receipt of property through restitution is highly related to the probability of an individual to be entrepreneur. This is unsurprising since bank lending for financing new firms is very uncommon in transition economies (e.g. McMillan and Woodruff, 2002). Moreover, even the official costs to

\footnotetext{
${ }^{48}$ According to Beck and Laeven (2005, Tab. 1), there is a large variation in share of natural resource exports in GDP, ranging from about 1 percent in Albania, Latvia and Moldavia to 32 percent in Turkmenistan and 55 percent in Tajikistan.

${ }^{49}$ According to a survey study carried out in early 1993 (Earle and Sakova, 2000, Tab. 1), there is substantial variation in the share of entrepreneurs across transition countries. About 20 percent of individuals reported self-employment in Poland, between 7.5 and 10.5 percent in Bulgaria, Czech Republic, Hungary and Slovakia, and only 2.5 percent in Russia. Roughly, a third of the self-employed also employ other people.
} 
start a business (taking issues like corruption aside) are often extraordinarily high. For instance, in Russia in 1999, it took 20 procedures and about two month to start a business, amounting to entry costs (including time costs) as a fraction of GDP of 43 percent, whereas in the U.S. it only took 4 procedures, 4 days and gave rise to costs of 1.7 percent of GDP (Djankov et al., 2002, Tab. III). This is consistent with our results on the role of entry barriers in a resource-abundant oligarchic economy.

\section{Concluding Remarks}

The emergence of a new ruling class and changing political institutions are as key to economic development as structural change from primary goods to manufacturing production. This was obvious to classical economists thinking about the sources of growth and the principles of political economy in 18/19th century in Europe. The presented paper has formalized this idea in a dynamic equilibrium model of economic growth and political change. In our model, while natural resources are the key factor in primary goods production, development and structural change is driven by capital investments into manufacturing firms. The level of such investments depends on the number of individuals who have both an economic interest in and the economic means for entrepreneurial activities. The means must be earned in the primary goods sector. How much of the income from primary goods production is left for entrepreneurial investment depends on the rents kept by the owners of the natural resources. Therefore, the distribution of resources and the share of the primary goods sector in total production are key variables in the process of development. The resource distribution is of particular importance as long as the primary goods sector has a substantial size and manufacturing productivity is low. Later, when the manufacturing sector dominates, the means for further expansion of manufacturing activity come from this sector itself.

Oligarchic ownership of natural resources is thus a main obstacle to economic development. It is also an obstacle to political change. Since rents in the primary goods sector diminish the opportunities for non-owners to develop entrepreneurial activity, they dampen the chances that a new political force - the owners of manufacturing 
firms (entrepreneurial class) - emerges and shapes policy and institutions. The entrepreneurial class does not share the resource owners' interests against promotion of the manufacturing sector by educating the work force, investing in infrastructure, reforming financial institutions and fighting corruption. We have demonstrated that the historical evidence on the two Americas in the 19th century supports each economic and political channel of our theory on a negative relationship between land inequality and long-run growth. Insofar, this paper provides a novel microfounded politico-economic explanation of the diverging development in North- and Latin America.

While at the empirical level, the innovation of the paper is its systematic account for a richer set of economic and political aspects than other studies so far, the theoretical innovation lies in the modelling of the role of entrepreneurial activity. By this, the presented theoretical analysis may contribute to the understanding of development in any region or epoch in which structural change from natural resource based production to competitive capitalistic industries is decisive. For instance, one could apply our two-class politico-economic model to European development from rural societies to industrialized economies ruled by bourgeois forces rather than landed aristocrats. Despite similarities there is also variation across European countries. For an extreme case, one may think of Russia where modernization of institutions as well as industrial revolution were missing. In more recent time, Korea and the Philippines have been considered as examples illustrating the negative role of unequal land distribution for economic development. ${ }^{50}$ Obviously, also the role of the ownership structure in the gold-, oil-, uranium-, tin- or diamond-industry for the poor development of African countries would deserve a systematic examination within our framework. Unfortunately, we don't have access to similar rich historical evidence like that on the Americas. To give one example for how our analysis carries over to other continents and times, we have briefly discussed the role of oligarchs in transition economies. It is an irony of history that the country which in 1917 defied Marx's view on the sequence

\footnotetext{
${ }^{50}$ See Bénabou (1996) who takes up a puzzle raised by Lucas (1993) that Korea and the Philippines, which were very similar in terms of many macroeconomic indicators but not in land inequality in the early 1960s, grew at very different annual rates (six vs. two percent) in the aftermath.
} 
of stages of societies, after the breakdown of communism to some extent proved the conclusion which Marx drew from earlier history - from ancient Greeks over Germanic peoples to oversea colonies: "A conquering population distributes the land among the conquerers and imposes thus a certain distribution and property structure; determines from there the production". ${ }^{51}$

\section{Appendix}

\section{A. Wage Setting in the Manufacturing Sector}

In this appendix we show that wage setting in the manufacturing sector, $w_{t}^{Y}=\alpha A_{t}$, can be rationalized in at least two ways. First, consider Nash bargaining between entrepreneurs and workers. According to production function (3), the current profit per unit of labor is given by $A-w^{Y}$. Thus, when outside options of both parties are zero, wage rate $w^{Y}=\alpha A$ maximizes the Nash product $\left(w^{Y}\right)^{\alpha}\left(A-w^{Y}\right)^{1-\alpha}$, where $\alpha \in(0,1)$ reflects the bargaining power of workers and $1-\alpha$ that of entrepreneurs.

Second, suppose output of a single entrepreneur is given by $y=A e l^{y}$, where $e$ denotes unobservable effort level per worker. Assume that disutility of effort provision enters workers' utility additively. Let this disutility be given by a function $z(e, w, \tilde{w})$, where $\tilde{w}$ is a reference wage which workers perceive as fair, as in Akerlof and Yellen (1990). It is plausible to assume that $\tilde{w}$ is related to productivity per efficiency unit of labor, $A$. So let the fair wage in $t$ be given by $\tilde{w}_{t}=\alpha A_{t}, 0<\alpha<1$. It is also reasonable to assume that a higher gap between the actual wage $w$ and $\tilde{w}$ raises disutility of effort. For concreteness, we specify $z(e, w, \tilde{w})=0.5 e^{2}-e-e \log (w / \tilde{w})$, i.e., workers choose effort

$$
\begin{aligned}
\tilde{e}(w, \tilde{w}) & \equiv \arg \min _{e \geq 0} z(e, w, \tilde{w}) \\
& =1+\log (w / \tilde{w}) .
\end{aligned}
$$

\footnotetext{
${ }^{51}$ Karl Marx (1953). Grundrisse der Kritik der Politischen Ökonomie (Rohentwurf 1857 - 1858), Berlin: Dietz, p. 17; own translation.
} 
Entrepreneurs now set wage rate $w^{Y}$ to minimize wage costs per unit of effort, $w / \tilde{e}$. With $\tilde{e}=1+\log (w / \tilde{w})$, this indeed leads to $w^{Y}=\tilde{w}=\alpha A$; moreover, workers provide effort $e=\tilde{e}(\tilde{w}, \tilde{w})=1$, i.e., we have $y=A l^{y}$ as given by (3).

\section{B. Proofs}

Proof of Lemma 1: First, recall that individual labor supply is given by $L^{X}=N^{X} s$ and that $1 / \rho=n^{R}\left(=N^{R} / N^{L}\right)$ due to normalization $R=N^{L}$. By combining this with $L^{X}=N^{R} l^{x}$, we have $l^{x}=s N^{X} / N^{R}$ and $l^{x} / \rho=s n^{X}$. Moreover, inverting the labor supply function $s=\bar{s} w^{1 / \vartheta}$ yields $w=(s / \bar{s})^{\vartheta}$. Hence, (5) can be rewritten as:

$$
f^{\prime}\left(s n^{X}\right)=\left(1+\frac{\vartheta}{N^{L} n^{R}}\right)\left(\frac{s}{\bar{s}}\right)^{\vartheta}
$$

This implicitly defines labor supply $\tilde{s}\left(n^{X}, n^{R}\right)$ as function of $n^{X}$ and $n^{R}$ with $\partial \tilde{s} / \partial n^{X}<$ 0 (observing $\left.f^{\prime \prime}<0\right)$ and $\partial \tilde{s} / \partial n^{R}>0(=0)$ if $\vartheta>0\left(=0\right.$, resp.). Since $w^{X}=$ $\left(\tilde{s}\left(n^{X}, n^{R}\right) / \bar{s}\right)^{\vartheta}$, this confirms the comparative-static results with respect to $I^{X}=$ $w^{X} s\left(w^{X}\right)$. Moreover, $-\left(\partial \tilde{s} / \partial n^{X}\right)\left(n^{X} / s\right) \leq 1$, where strict inequality holds if $\vartheta>0$. Thus, $\partial L^{X} / \partial n^{X}=\partial\left(\tilde{s} n^{X} N^{L}\right) / \partial n^{X}>0$ if $\vartheta>0$.

The profits of each resource owner are given by $\pi^{x}=\rho f\left(l^{x} / \rho\right)-w^{X} l^{x}$. Using $l^{x} / \rho=s n^{X}, l^{x}=s N^{X} / N^{R}=s n^{X} / n^{R}, w^{X}=(s / \bar{s})^{\vartheta}$ and $\rho=1 / n^{R}$ we can write

$$
\pi^{x}=\frac{1}{n^{R}}\left[f\left(s n^{X}\right)-\frac{s^{\vartheta+1}}{\bar{s}^{\vartheta}} n^{X}\right]
$$

where $s=\tilde{s}\left(n^{X}, n^{R}\right)$. Hence,

$$
\frac{\partial \pi^{x}}{\partial n^{X}}=\frac{1}{n^{R}}\left[f^{\prime}\left(s n^{X}\right)\left(\frac{\partial \tilde{s}}{\partial n^{X}} n^{X}+s\right)-(\vartheta+1)\left(\frac{s}{\bar{s}}\right)^{\vartheta} \frac{\partial \tilde{s}}{\partial n^{X}} n^{X}-\left(\frac{s}{\bar{s}}\right)^{\vartheta} s\right] .
$$

Substitute (A.1) into (A.3) to obtain

$$
\frac{\partial \pi^{x}}{\partial n^{X}}=\frac{1}{n^{R}}\left(\frac{s}{\bar{s}}\right)^{\vartheta} s \vartheta\left[\frac{1}{N^{R}}\left(\frac{\partial \tilde{s}}{\partial n^{X}} \frac{n^{X}}{s}+1\right)-\frac{\partial \tilde{s}}{\partial n^{X}} \frac{n^{X}}{s}\right]
$$


Since $\partial \tilde{s} / \partial n^{X}<0$ and $\left(\partial \tilde{s} / \partial n^{X}\right)\left(n^{X} / s\right)+1 \geq 0$ (recall (A.1) and the properties of $\left.\tilde{s}\right)$, $\partial \pi^{x} / \partial n^{X}>0$ if $\vartheta>0$. In an analogous way, we get

$$
\frac{\partial\left[f\left(s n^{X}\right)-\frac{s^{\vartheta+1}}{\bar{s}^{\vartheta}} n^{X}\right]}{\partial n^{R}}=\left(\frac{s}{\bar{s}}\right)^{\vartheta} n^{X} \vartheta\left(\frac{1}{N^{R}}-1\right) \frac{\partial \tilde{s}}{\partial n^{R}} \geq 0
$$

with strict inequality if $\vartheta>0$, since $\partial \tilde{s} / \partial n^{R}>0$ if $\vartheta>0$ and $N^{R}>1$. Using this in (A.2), we have $\partial \pi^{x} / \partial n^{R}<0$ for any $\vartheta \geq 0$. This concludes the proof.

Proof of Proposition 1: Stability condition $\partial a / \partial A<1$ implies that $A\left(G_{t+1}\right) \leq$ $A\left(G_{t+2}\right)$ if $G_{t+2} \geq G_{t+1}$. $A_{1}<A\left(G_{2}\right)$ implies $A_{1}<A_{2}<A\left(G_{2}\right) \leq A\left(G_{3}\right)$. Repeating the argument we conclude that $A_{t}$ increases over time. Then, the results on $\pi^{E *}, n^{E *}$, $Y^{*}$ and $n^{X *}$ follow from (10), (11), (13), (14). For the result on $\pi^{x *}$ use Lemma 1.

Proof of Proposition 2: Follows from (7) together with $n_{t}^{E *}=\xi_{t}^{*},(10),(11)$, (13), (14) and Lemma 1.

Proof of Lemma 2: According to (16), $l_{t}^{y c}=\sqrt{2\left(\eta I_{t-1}^{X}-\xi-\bar{k}\right)}<l^{y *}$ when credit constraints are binding. Moreover, $\eta I_{t-1}^{X}=k\left(\xi, l^{y c}\right)$. Hence, under credit constraints, profits are:

$$
\begin{aligned}
\pi^{y c}(\xi) & =(1-\alpha) A_{t} l_{t}^{y c}-0.5\left(l_{t}^{y c}\right)^{2}-\xi-\bar{k} \\
& =(1-\alpha) A_{t} \sqrt{2\left(\eta I_{t-1}^{X}-\xi-\bar{k}\right)}-\eta I_{t-1}^{X}
\end{aligned}
$$

Since $\pi^{y c}(\xi)$ is increasing in $l^{y c}$ and $l^{y c}<l^{y *}$, we have $\pi^{y c}<\pi^{y *}$, and $\pi^{y c}$ rises in both $\eta$ and $I^{X}$. Laborers who work in the $X$-sector in their first period of life become entrepreneur in $t$ if $\pi_{t}^{y c}(\xi) \geq 0$, which is equivalent to

$$
\xi \leq \eta I_{t-1}^{X}-0.5\left(\frac{\eta I_{t-1}^{X}}{(1-\alpha) A_{t}}\right)^{2}-\bar{k} \equiv \xi_{t}^{c}
$$

according to (A.5). Since $\pi^{y c}$ declines with $\xi$ and $\pi^{y c}<\pi^{y *}$ for any $(A, \xi)$, it is immediate that $\xi_{t}^{c}<\xi_{t}^{*}$. Moreover, since $\pi^{y c}$ is increasing in both $\eta$ and $I^{X}, \xi^{c}$ is increasing in $\eta$, and, according to Lemma 1 , increasing in $n^{R}$ (provided $\vartheta>0$ ) as 
well as decreasing in $n^{X}$. Moreover, recall that $I^{X}$ is independent of $A$ and $\bar{k}$. Thus, according to (A.6), $\xi^{c}$ is increasing in $A$ and decreasing in $\bar{k}$. This concludes the proof.

Proof of Lemma 3: The properties of $\tilde{n}^{E c}\left(A, n^{X}, n^{R}, \eta, \bar{k}\right)$ follow from (11), (17) and Lemma 2. (Note that (17) implies $\partial \tilde{n}^{E c} / \partial n^{X}=-\left(\xi^{*}-\xi^{c}\right)+n^{X}\left(\partial \xi^{c} / \partial n^{X}\right)$, where $\xi^{*}>\xi^{c}$ and $\partial \xi_{t}^{c} / \partial n^{X}<0$ from Lemma 2.) $\tilde{Y}^{c}\left(A, n^{X}, n^{R}, \eta, \bar{k}\right)$ has the same properties as $\tilde{n}^{E c}$, whereas the opposite holds for $\tilde{n}^{X}\left(A, n^{X}, n^{R}, \eta, \bar{k}\right)$. This follows from (18) and (19), by accounting for the following facts. According to the proof of Lemma $1, I^{X}$ is a monotonic transformation of $\tilde{s}\left(n^{X}, n^{R}\right)$. Using this in (16) we see that $l^{y c}$ is independent of $A$ and reacts to $n^{X}, n^{R}, \eta, \bar{k}$ in the same way as stated for $\xi^{c}$ in Lemma 2. As a consequence, $Q \equiv \int_{0}^{\xi^{c}} l^{y c} d \xi$ has the same properties as $\xi^{c}$. Moreover, like $\xi^{*}$ also $\xi^{*} l^{y *}$ is a positive function of $A$ and negatively depends on $\bar{k}$ (use $l^{y^{*}}=(1-\alpha) A$ from (9)). Finally, $Q<\xi^{*} l^{y *}$. $\tilde{a}\left(A, n^{X}, G, n^{R}, \eta, \bar{k}\right)$ is increasing in $A, \eta, G$, and, if $\vartheta>0, n^{R}$, and decreasing in $n^{X}$ and $\bar{k}$, according to $(7),(20)$ and the properties of $\tilde{n}^{E c}$.

Proof of Proposition 3: The comparative-static results on $n^{E c}$ and $Y^{c}$ follow, by observing Lemma 3, from the dynamic system described by equations (17)-(20). With respect to the profits of entrepreneurs, first note that $\pi^{y c}$, given by (A.5), and $\pi^{y *}$, given by (10), are increasing in $A$ and decreasing in $\bar{k}$. Second, note that $\pi^{y c}$ is increasing $\eta$ and $I^{X}$, where $I^{X}$ is positively related to $n^{R}$ (for $\vartheta>0$ ) and negatively related to $n^{X}$, according to Lemma 1. ( $\pi^{y *}$ does not depend on $\eta$ or $I^{X}$.) The results on profits of resource owners follow from Lemma 1. This concludes the proof.

Proof of Proposition 4: First, because $G_{t}^{R}=0,(23)$ reduces to

$$
G_{t}=\frac{\left(\Pi_{t-1}^{Y} / N^{L}\right) G_{t}^{E}}{\Pi_{t-1}^{X} / N^{L}+\Pi_{t-1}^{Y} / N^{L}} .
$$

Also note that $\Pi^{X} / N^{L}=n^{R} \pi^{x}$ and, in the constrained regime,

$$
\frac{\Pi_{t}^{Y}}{N^{L}}=n_{t-1}^{X} \int_{0}^{\xi_{t}^{c}} \pi_{t}^{y c}(\xi) d \xi+\left(1-n_{t-1}^{X}\right) \int_{0}^{\xi_{t}^{*}} \pi_{t}^{y *}(\xi) d \xi
$$


Proposition 4 is proven by deriving three lemmas. The first lemma characterizes $G^{E}$ (focussing on interior solutions throughout), whereas the latter two lemmas characterize $\Pi^{X} / N^{L}$ and $\Pi^{Y} / N^{L}$, respectively.

Lemma A.1. For any $t>1$ : (i) In the unconstrained regime, $G_{t}^{E}$ is decreasing in $\bar{k}$ and independent of $n^{R}$. (ii) In the constrained regime, $G_{t}^{E}$ is decreasing in $\bar{k}$, and increasing in both $n^{R}$ and $\eta$. (iii) For any set of initial conditions, $G_{t}^{E}$ is smaller in the constrained regime than in the unconstrained regime.

Proof. The first-order condition for maximization problem (24) reads

$$
(1-\alpha)^{2} \frac{\partial a\left(n_{t-1}^{E}, G_{t}, A_{t-1}\right)}{\partial G} a\left(n_{t-1}^{E}, G_{t}, A_{t-1}\right)=0.5
$$

which implicitly defines $G_{t}^{E}$ as function of $n_{t-1}^{E}$ and $A_{t-1}$. Using (A.9) and the secondorder condition we calculate $\partial G_{t}^{E} / \partial n_{t-1}^{E}>0$ and $\partial G_{t}^{E} / \partial A_{t-1}>0$, since $\partial^{2} a / \partial G \partial n^{E} \geq$ 0 and $\partial^{2} a / \partial G \partial A \geq 0$ was assumed. Combining this with $\partial n^{E *} / \partial \bar{k}<0, \partial n^{E *} / \partial n^{R}=0$ (from Proposition 2) and with $\partial n^{E c} / \partial \bar{k}<0, \partial n^{E c} / \partial n^{R}>0, \partial n^{E c} / \partial \eta>0$ (from Proposition 3) we obtain parts (i) and (ii) of Lemma A.1. Finally, recalling from the proof of Lemma 2 that $\xi^{c}<\xi^{*}=n^{E *}$ we conclude from (17) that $n^{E c}<n^{E *}$. Thus, for given initial conditions, $n^{E}$ and because of (7) also $A$ is higher in the unconstrained regime than in the constrained regime in any point of time. Part (iii) then follows from $\partial G_{t}^{E} / \partial n_{t-1}^{E}>0$ and $\partial G_{t}^{E} / \partial A_{t-1}>0$.

Lemma A.2. If $\vartheta>0$, then for any $t>1$ : (i) $\Pi_{t-1}^{X} / N^{L}$ is decreasing in $n^{R}$, where the impact of an increase in $n^{R}$ is larger in the constrained regime than in the unconstrained regime. (ii) For any set of initial conditions, $\Pi_{t-1}^{X} / N^{L}$ is higher in the constrained regime than in the unconstrained regime.

Proof. Using $n^{R} \rho=1$ and $s=\tilde{s}\left(n^{X}, n^{R}\right)$ [as given by (A.1)], (A.2) implies

$$
n^{R} \pi_{t}^{x}=f\left(\tilde{s}\left(n_{t}^{X}, n^{R}\right) n_{t}^{X}\right)-\frac{\tilde{s}\left(n_{t}^{X}, n^{R}\right)^{\vartheta+1}}{\bar{s}^{\vartheta}} n_{t}^{X}
$$

Differentiating the right-hand side of (A.10) with respect to $n^{R}$, and substituting (A.1), 
we find that

$$
\frac{\partial\left[n^{R} \pi_{t}^{x}\right]}{\partial n^{R}}=\left(\frac{s}{\bar{s}}\right)^{\vartheta} \vartheta\left[\left(\frac{1}{N^{R}}-1\right)\left(\frac{\partial \tilde{s}}{\partial n_{t}^{X}} \frac{\partial n_{t}^{X}}{\partial n^{R}}+\frac{\partial \tilde{s}}{\partial n^{R}}\right) n_{t}^{X}+\frac{s}{N^{R}} \frac{\partial n_{t}^{X}}{\partial n^{R}}\right]
$$

where $\partial n_{t}^{X} / \partial n^{R}=0$ in the unconstrained regime, according to Proposition 2, and $\partial n_{t}^{X} / \partial n^{R}<0$ in the constrained regime, according to Proposition 3. Recalling $\partial \tilde{s} / \partial n^{X}<$ 0 and, if $\vartheta>0, \partial \tilde{s} / \partial n^{R}>0$ confirms part (i). For part (ii), note that, for given initial conditions, $n_{t}^{X}$ is lower in the unconstrained regime than in the constrained regime. (Use $\xi^{c} l^{y c}<\xi^{*} l^{y *}$ when comparing (19) to (14).) Hence, according to Lemma 1, profits of resource owners are lower in the unconstrained regime than in the constrained regime in any point of time.

Lemma A.3. If $\vartheta>0$, then for any $t>1$ : (i) $\Pi_{t-1}^{Y} / N^{L}$ is increasing in $n^{R}$ in the constrained regime, and independent of $n^{R}$ in the unconstrained regime. (ii) For any set of initial conditions, $\Pi_{t-1}^{Y} / N^{L}$ is lower in the constrained regime than in the unconstrained regime.

Proof. That $\Pi_{t-1}^{Y} / N^{L}$ is independent of $n^{R}$ in the unconstrained regime immediately follows from part (i) of Proposition 2. For the constrained regime, differentiating (A.8) yields

$\frac{\partial\left(\frac{\Pi^{Y}}{N^{L}}\right)}{\partial n^{R}}=-\frac{\partial n^{X}}{\partial n^{R}}\left[\int_{0}^{\xi^{*}} \pi^{y *} d \xi-\int_{0}^{\xi^{c}} \pi^{y c} d \xi\right]+n^{X} \frac{\partial\left(\int_{0}^{\xi^{c}} \pi^{y c} d \xi\right)}{\partial n^{R}}+\left(1-n^{X}\right) \frac{\partial\left(\int_{0}^{\xi^{*}} \pi^{y *} d \xi\right)}{\partial n^{R}}$

The first term in this sum is positive, since $\xi^{c}<\xi^{*}, \pi^{y c}<\pi^{y *}$ and, according to Proposition 3, $\partial n^{X} / \partial n^{R}<0$. The second part of the sum is positive since $\xi^{c}$ and $\pi^{y c}$ rise with $n^{R}$, according to Lemma 2 and the proof of Proposition 3, respectively. The last term vanishes, since $\pi^{y *}$ and $\xi^{*}$ are independent of $n^{R}$ (Proposition 2).

Now consider the implications of Lemma A.1-A.3 for (A.7). First, the impact of an increase in $n^{R}$ on $G_{t}$ (part (i) of Proposition 4) follows by combining parts (i) and (ii) of Lemma A.1 with the first parts of Lemma A.2 and A.3. The other comparative-static results in part (i) of Proposition 4 follow from parts (i) and (ii) of Lemma A.1 together with Propositions 2 and 3. Part (ii) of Proposition 4 follows from $\partial G_{t}^{E} / \partial n_{t-1}^{E}>0$ 
and $\partial G_{t}^{E} / \partial A_{t-1}>0$ (see proof of Lemma A.1) and the fact that, along with rising $n^{X}$ and $A$, entrepreneurial profits, $\pi^{y *}, \pi^{y c}$, as well as the share of entrepreneurs, $n^{E *}$, $n^{E c}$, increase over time whereas profits of resource owners decrease. (Recall Lemma 1, (10) and (11) for the relevant effects in the unconstrained equilibrium and the proofs of Lemma 3 and Proposition 3 for the effects in the constrained regime, respectively.) Part (iii) of Proposition 4 follows from the final parts of Lemma A.1-A.3. This concludes the proof.

Remark 1. Proposition 4 also holds if we alternatively assume that $G_{t}^{c}$ is based on political representation of the entrepreneurial elite by a credit-constrained entrepreneur (who worked in the $X$-sector in the first period of life) with high ability. To see this, let us consider $\xi=0$ for concreteness. A credit-constrained entrepreneur with $\xi=0$ maximizes $\pi_{t}^{E c}(0)-G_{t} / 2$ in $t$; that is, (s)he solves

$$
\max _{G \geq 0}(1-\alpha) a\left(n_{t-1}^{E c}, G_{t}, A_{t-1}\right) \sqrt{2\left(\eta I_{t-1}^{X}-\bar{k}\right)}-\eta I_{t-1}^{X}-0.5 G_{t}
$$

according to (A.5) and (7). This leads to first-order condition

$$
(1-\alpha) \frac{\partial a\left(n_{t-1}^{E c}, G_{t}, A_{t-1}\right)}{\partial G} \sqrt{2\left(\eta I_{t-1}^{X}-\bar{k}\right)}=0.5
$$

Equ. (A.9) implicitly defines $G_{t}^{E}$ as function of $I_{t-1}^{X}, n_{t-1}^{E c}, A_{t-1}, \eta$ and $\bar{k}$. Since part (i) of Lemma A.1, as well as Lemma A.2 and A.3 are unaffected, it suffices to show that parts (ii) and (iii) of Lemma A.1 hold. Note first that the argument applied in proving part (iii) of Lemma A.1 and part (ii) of Proposition 4 also hold under the weak (rather than strict) inequalities $\partial G_{t}^{E} / \partial n_{t-1}^{E c} \geq 0, \partial G_{t}^{E} / \partial A_{t-1} \geq 0$. (A.9) indeed implies that the latter two properties hold. For part (ii) of Lemma A.1, first note that $\partial G_{t}^{E} / \partial I_{t-1}^{X}>0, \partial G_{t}^{E} / \partial \eta>0$ and $\partial G_{t}^{E} / \partial \bar{k}<0$. Moreover, recall from Proposition 3 that $\partial n^{E c} / \partial n^{R}>0, \partial n^{E c} / \partial \eta>0$ and $\partial n^{E c} / \partial \bar{k}<0$, whereas the opposite holds for $n^{X}$. Observing these effects on $n^{X}$ and applying Lemma 1 then reveals $\partial I^{X} / \partial n^{R}>0$, $\partial I^{X} / \partial \eta>0$ and $\partial I^{X} / \partial \bar{k}<0$. This confirms part (ii) of Lemma A.1. 


\section{References}

Acemoglu, Daron, Simon Johnson and James A. Robinson (2004). Institutions as the Fundamental Cause for Long-run Growth, in: Philippe Aghion and Steven Durlauf (eds), Handbook of Economic Growth, forthcoming.

Aghion, Philippe and Patrick Bolton (1997). A Theory of Trickle-Down Growth and Development, Review of Economic Studies 64, 151-172.

Aghion, Philippe, Peter Howitt and David Mayer-Foulkes (2005). The Effect of Financial Development on Convergence: Theory and Evidence, Quarterly Journal of Economics 120, 173-222.

Akerlof, George A. and Janet Yellen (1990). The Fair Wage-Effort Hypothesis and Unemployment, Quarterly Journal of Economics 105, 255-283.

Bairoch, Paul (1982). International Industrialization Levels from 1750 to 1980, Journal of European Economic History 11, 269-333.

Banerjee Abhijit V. and Andrew F. Newman (1993). Occupational Choice and the Process of Development, Journal of Political Economy 101, 274-298.

Bauer, Arnold J. (1979). Rural Workers in Spanish America: Problems of Peonage and Oppression, Hispanic American History Review 59, 34-63.

Beck, Thorsten and Luc Laeven (2005). Institution Building and Growth in Transition Economies, World Bank (mimeo).

Bénabou, Roland (1996). Inequality and Growth, NBER Macroeconomics Annual, 11-74.

Bernanke, Ben, and Mark Gertler, 1989, Agency Costs, Net Worth, and Business Fluctuations, American Economic Review 79, 14-31.

Centeno, Miguel A. (1997). Blood and Debt: War and Taxation in NineteenthCentury Latin America, American Journal of Sociology 102, 1565-1605.

Chong, Alberto and Mark Gradstein (2005). Inequality and Institutions, BenGurion University (mimeo).

Djankov, Simeon, Rafael La Porta, Florenzio Lopez-de-Silanes and Andrei Shleifer (2002). The Regulation of Entry, Quarterly Journal of Economics 116, 1-37. 
Earle, John S. and Zuzana Sakova (2000). Business Start-ups or Disguised Unemployment? Evidence on the Character of Self-employment from Transition Economies, Labour Economics 7, 575-601.

Easterly, William and Ross Levine (2003). Tropics, Germs, and Crops: How Endowments Influence Economic Development, Journal of Monetary Economics 50, 3-39.

Engerman, Stanley L., Stephen Haber and Kenneth L. Sokoloff (2000). Inequality, Institutions, and Differential Paths of Growth Among New World Economies, in: Claude Menard (ed), Institutions, Contracts, and Organizations, Edward Elgar, Cheltenham.

Engerman, Stanley L. and Kenneth L. Sokoloff (2005). Colonialism, Inequality, and Long-run Paths of Development, NBER Working Paper No. 11057.

Falkinger, Josef and Volker Grossmann (2005). Institutions and Development: The Interaction between Trade Regime and Political System, Journal of Economic Growth 10, 229-270.

Field, Alexander J. (1979). Economic and Demographic Determinants of Educational Commitment: Massachusetts, 1855, Journal of Economic History 39, 439-460.

Galor, Oded and Omer Moav (2006). Das Human Kapital: A Theory of the Demise of the Class Structure, Review of Economic Studies, forthcoming.

Galor, Oded and Andrew Mountford (2003). Trading Population for Productivity, Working Paper 2004-16, Brown University, Department of Economics.

Galor, Oded, Omer Moav and Dietrich Vollrath (2005). Land Inequality and the Emergence of Human Capital Promoting Institutions, Brown University Economics Working Paper No. 05-03.

Galor, Oded and Joseph Zeira (1993). Income Distribution and Macroeconomics, Review of Economic Studies 60, 35-52.

Gerber, Jim (1991). Public School Expenditures in the Plantation States, 1910, Explorations in Economic History 28, 309-322.

Glaeser, Edward L., Rafael La Porta, Florencio Lopez-de-Silanes and Andrei Shleifer (2004). Do Institutions Cause Growth? Journal of Economic Growth 9, 271-303. 
Gradstein, Mark and Moshe Justman (1999). Industrial Revolution, Political Transition and the Subsequent Decline in Inequality in Nineteenth-Century Britain, Explorations in Economic History 36, 109-127.

Gradstein, Mark (2004). Inequality, Democracy, and the Protection of Property Rights, Ben-Gurion University (mimeo).

Guriev, Sergei and Andrei Rachinsky (2004). Oligarchs: The Past or Future of Russian Capitalism?, World Bank (mimeo).

Gylfason, Thorvaldur (2001). Natural Resources, Education and Economic Development, European Economic Review 45, 847-859.

Gylfason, Thorvaldur Tryggvi T. Herbertsson and Gylfi Zoega (1999). A Mixed Blessing: Natural Resources and Economic Growth, Macroeconomic Dynamics 3, 204225 .

Hatton, Timothy J. and Jeffrey G. Williamson (1992). What Explains Wage Gaps between Farm and City? Exploring the Todaro Model with American Evidence, 18901941, Economic Development and Cultural Change 40, 267-294.

Hazen, Dan C. (1978). The Politics of Schooling in the Nonliterate Third World: The Case of Highland Peru, History of Education Quarterly 18, 419-443.

Katz, Friedrich (1974). Labor Conditions on Haciendas in Porfirian Mexico: Some Trends and Tendencies, Hispanic American History Review 54, 1-47.

Keith, S. (1978). An Historical Overview of the State and Educational Policy in Jamaica, Latin American Perspectives 5, 37-52.

Kronenberg, Tobias (2004). The Curse of Natural Resources in the Transition Economies, Economics of Transition 12, 399-426.

Lane, Philip R. and Aaron Tornell (1996). Power, Growth and the Voracity Effect, Journal of Economic Growth 1, 213-241.

Lindert, Peter H. (2004). Growing Public. Social Spending and Economic Growth Since the Eighteenth Century, Vol. I, Cambridge: Cambridge University Press.

Loy, J.M. (1971). Primary Education during the Columbian Federation: The School Reform of 1870, Hispanic American History Review 51, 275-294. 
Lucas, Robert E. (1993). Making a Miracle, Econometrica 61, 251-272.

Maddison, Angus (2003). The World Economy: Historical Statistics, OECD, Paris.

Matsuyama, Kiminori (1992). Agricultural Productivity, Comparative Advantage, and Economic Growth, Journal of Economic Theory 58, 317-34.

Matsuyama, Kiminori (2003). Financial Market Globalization, Symmetry-Breaking, and Endogenous Inequality of Nations, Econometrica 72, 853-884.

McBride, George (1936). Chile: Land and Society, New York: American Geographical Society.

McMillan, John and Christopher Woodruff (2002). The Central Role of Entrepreneurs in Transition Economies, Journal of Economic Perspectives 16, 153-170.

Mehlum, Halvor, Karl Moene and Ragnar Torvik (2005). Institutions and the Resource Curse, Economic Journal, forthcoming.

Mellafe, R. (1971). The Latifundio and the City in Latin American History, Toronto: University of Toronto Press.

Morse, Richard M. (1975). The Development of Urban Systems in the Americas in the Nineteenth Century, Journal of Interamerican Studies and World Affairs 17, 4-26.

Mosk, Sanford A. (1951). Latin America versus United States, American Economic Review 41, 367-383.

Nicholls, William H. (1956). Some Foundations of Economic Development in the Upper East Tennesse Valley, 1850-1900. II, Journal of Political Economy 44, 400-415.

North, Douglass C. (1961). The Economic Growth of the United States 1790-1860, Englewood Cliffs, NJ: Prentice-Hall.

Piketty Thomas (1997). The Dynamics of the Wealth Distribution and the Interest Rate with Credit Rationing, Review of Economic Studies 64, 173-189.

Pregger-Román, Charles G. (1983). The Origin an Development of the Bourgeoisie in Nineteenth-Century Chile, Latin American Perspectives 37/38, 39-59.

Reimers, Fernando (2004). The Politics of Learning: The Struggle for Educational Opportunity in Latin America, in: Bulmer-Thomas, Victor Bulmer-Thomas, John Coatsworth and Roberto Cortes Conde (eds), Cambridge Economic History of Latin 
America, Cambridge: Cambridge University Press.

Ridings, Eugene W. (1977). Interest Groups and Development: The Case of Brazil in the Nineteenth Century, Journal of Latin American Studies 9, 225-250.

Robinson, James A., Ragnar Torvik and Thierry Verdier (2005). Political Foundations of the Resource Curse, Economic Journal (forthcoming).

Rosenberg, Nathan and Manuel Trajtenberg (2001). A General Purpose Technology at Work: The Corliss Steam Engine in the Late 19th Century US, NBER Working Paper No. 8485.

Sachs, Jeffrey D. and Andrew M. Warner (2001). The Curse of Natural Resources, European Economic Review 45, 827-838.

Schweigert, Thomas E. (2004). Agricultural Wage Rates Under Forced and Free labour: Pre-1944 and Post 1954 Guatemala, Journal of Agrarian Change 4, 532-552.

Sokoloff, Kenneth L. and Stanley L. Engerman (2000). Institutions, Factor Endowments, and Paths of Development in the New World, Journal of Economic Perspectives 14, 217-232.

Stein, Stanley J. and Shane J. Hunt (1971). Principal Currents in the Economic Historiography of Latin America, Journal of Economic History 31, 222-253.

Torvik, Ragnar (2002). Natural Resources, Rent Seeking and Welfare, Journal of Development Economics 67, 455-470.

Wright, Gavin (1987). The Economic Revolution in the American South, Journal of Economic Perspectives 161-178. 